\title{
Paläoböden als Klimazeugen - dargestellt an Löß-Boden-Abfolgen des Karpatenbeckens
}

\author{
Von Arnt Bronger, Kiel
}

\section{Mit 4 Abbildungen, 1 Tafel und 1 Tabelle}

$\mathrm{Z}$ us a m m e $\mathrm{f}$ a s sung. Für eine Löß-Boden-Stratigraphie und daraus folgend für eine pleistozäne Klimageschichte SE-Mitteleuropas eignen sich die großen Lößaufschlüsse im ungarischen und jugoslawischen Donauabschnitt infolge der sehr günstigen Aufschlußverhältnisse besonders gut. Außerdem sind hier die jungpleistozänen Böden — im Gegensatz zu den jungpleistozänen Böden NW-Mitteleuropas - den rezenten Böden des Karpatenbeckens genetisch-typologisch im ganzen recht ähnlich und dadurch auch untereinander gut vergleichbar. Da wesentliche diagnostische Merkmale, die bei rezenten Böden im Gelände erfaßbar sind, bei fossilen Böden verlorengingen, kommt der Mikromorphologie für die Aufhellung der Bodengenese eine besondere Bedeutung zu. Zusammenfassend war eine gesicherte stratigraphische Korrelation der jungpleistozänen Paläoboden-Abfolgen $F_{5}$ bis $F_{2}$ in diesem Raum möglich, wobei der $F_{5}$ dem basalen Braunerde-Lessivé des Profils von Unter-Wisternitz bzw. der basalen Braunerde des "Stillfrieder Komplexes“ stratigraphisch entspricht und damit in das Riß/Würm-Interglazial gestellt wird.

Für eine paläoklimatische Auswertung sind über die genaue bodenty pologische Ansprache hinaus Untersuchungen notwendig, die Aussagen über Art und Intensität der Verwitterung gestatten. Da hierfür die sonst üblichen bodenchemischen Methoden, einschließlich der Untersuchung der pedogenen Eisenoxide ausscheiden, bleibt nur der zeitraubende Weg der mineralogischen, besonders tonmineralogischen Untersuchungen. Danach ergab sich - zusammen mit den o.g. Befunden -, daß die altpleistozänen Böden $F_{11}, F_{10}$ und $F_{9}$ sowie der mittelpleistozäne $F_{6}$ (Taf. I), alle vom Typ des rubefizierten erdigen Braunlehms, zu den jungpleistozänen Böden der Genese und Verwitterungsintensität nach keine Analogie haben und der submediterranen bis subtropischen Bodenprovinz i. S. Kubienas entsprechen. Die innerwürmzeitlichen Tschernoseme (in Ausnahmen Braunerden) $\mathrm{F}_{4}$ bis $\mathrm{F}_{2}$ erreichen nach dem Ausmaß der pedochemischen Feintonbildung $(<0,2 \mu \mathrm{m})$ die Verwitterungsintensität der rezenten Böden gleichen Typs; sie repräsentieren daher in diesem Raum jeweils Warmzeiten (Perioden mit warmzeitlichem Klima, etwa vergleichbar dem heutigen von mehreren tausend Jahren Dauer).

$\mathrm{S} \mathrm{u} \mathrm{m} \mathrm{m} \mathrm{a} \mathrm{r} \mathrm{y.} \mathrm{The} \mathrm{major} \mathrm{loess} \mathrm{sections} \mathrm{of} \mathrm{the} \mathrm{Hungarian} \mathrm{and} \mathrm{Yugoslavian} \mathrm{Danubian} \mathrm{lowlands}$ are particularly well suited for establishing a comparative loess pedostratigraphy and, by inference, a record of the pleistocene climatic fluctuations of the southeastern part of Central Europe. As a rule, and contrary to the situation encountered with the soils of the northwestern part of Central Europe in upper pleistocene strata, the upper pleistocene soils of the Carpathian Basin are quite similar to the recent soils of the area, and in addition, mutually well comparable. Micromorphology here is of outstanding importance since essential diagnostic characteristics as observable with recent soils in the field disappeared in the case of fossil soils. In summarizing it may be said, that a reliable stratigraphic correlation of the $\mathrm{F}_{5}$ to $\mathrm{F}_{2}$ upper pleistocene paleosol sequences appears possible, with the $\mathrm{F}_{5}$ stratigraphically corresponding to the basal gray brown podzolic of the Dolní Věstonice section or the basal brown forest soil of the "Stillfried Komplex", respectively; hence the $\mathrm{F}_{5}$ represents the Riß/Würm-interglacial.

Furthermore paleoclimatic deductions imply, beyond typological statements, analytical research into the ways and intensity of weathering processes involved. As the habitual pedochemical methods, including the determination of pedogenic iron oxides, are not applicable only timeconsuming mineralogical, especially clay mineralogical analyses yield the results desired. I. e. the lower pleistocene soils $\mathrm{F}_{11}, \mathrm{~F}_{10}$ and $\mathrm{F}_{9}$, and the mid-pleistocene $\mathrm{F}_{6}$ soil (cf. planche I) are rubefied earthy braunlehms and thus not comparable to the upper pleistocene soils with regard to pedogenesis and weathering intensity but rather to those of the submediterranean to subtropical soil province sensu KUBIENA. The intra-würm age chernozems (and, exceptionally, the stratigraphically corresponding brown forest soils) $\mathrm{F}_{4}$ to $\mathrm{F}_{2}$ have the same weathering intensity as the recent soils of the same type judged from by the extent of pedochemical clay formation $(<0,2 \mu \mathrm{m})$; in the area studied they represented substantially warm periods (i. e. pronounced interstadial periods of several thousand years' duration and a climate more or less comparable to the present one). 


\section{Einführung und Zielsetzung}

In den letzten beiden Jahrzehnten wurden zahlreiche Versuche unternommen, für das Eiszeitalter, insbesondere für das Jungpleistozän eine Löß-Boden-(Chrono-)Stratigraphie zu erstellen und eine Klimageschichte für diesen Zeitabschnitt abzuleiten. Hierüber wurden auch in der letzten Zeit zahlreiche, oft sich widersprechende Ergebnisse mitgeteilt. Der Grund lag meistens darin, daß man sich fast ausschließlich auf den Geländebefund stützte, manchmal ergänzt durch einfache Bodenanalysen wie Humusbestimmungen, $\mathrm{pH}$-Werte oder die Untersuchung der pedogenen Eisenoxide, die aber für p a lä o pedologische Aussagen wertlos sind. Die Paläopedologie verlor dadurch im Vergleich zu den Nachbarwissenschaften, die ebenfalls wichtige Erkenntnisse zu den o. g. Fragestellungen liefern, immer mehr an Bedeutung.

Ziel dieses Absatzes ist es, Ergebnisse zu einer Löß-Boden-Stratigraphie und darauf aufbauend zu einer alt-, mittel- und vor allem jungpleistozänen Klimageschichte des Karpatenbeckens vorzulegen und sie kontroversen Ergebnissen aus anderen Teilen Mitteleuropas gegenüberzustellen. Im Vordergrund steht dabei weniger die Absicht, zu bestehenden $\mathrm{Hy}-$ pothesen neue hinzuzufügen, sondern die hier vertretenen Meinungen durch ein System sich gegenseitig stützender und kontrollierender Untersuchungen möglichst von verschiedenen Seiten zu belegen. Hierfür sollen einige kurze Ausführungen zu den Untersuchungen selbst gemacht werden. Denn bei unseren bisherigen Arbeiten an rezenten und fossilen Lößböden stellte sich heraus, daß nicht alle Methoden, die bei r e z e n t e n Böden Hinweise auf Genese und Verwitterungsintensität geben, entsprechende Resultate bzw. Rückschlüsse bei f o s sil en Böden erwarten lassen.

\section{Stratigraphie der Löß-Boden-Abfolgen im Karpatenbecken}

2.1. Zur Untersuchungsmethodik. - Die Bedeutung der Bodenmikromorphologie.

Für eine Löß-Boden-Stratigraphie und daraus folgend für eine pleistozäne Klimageschichte Südost-Mitteleuropas eignen sich die großen Lößprofile entlang dem rechten Steilufer der Donau im ungarischen und jugoslawischen Abschnitt in mehrfacher Hinsicht besonders gut ${ }^{\mathbf{1}}$ ). Einmal sind hier die fossilen Böden vor allem des Jungpleistozäns (Begründung Kap. 2.2.) jeweils durch mehrere Meter mächtige, sehr häufig sog. „typische“, nicht oder kaum verlagerte, stärker carbonathaltige Lösse getrennt (Taf. I). Dazu kann man die Paläoböden vor allem im Südteil des Karpatenbeckens entlang den Steilabfällen der Fruska Gora bzw. des Titeler Lößplateaus oft über Kilometer verfolgen. Die vergleichenden Geländeuntersuchungen ergaben u. a. ferner, daß in den meisten der großen hier untersuchten Lößprofilen die Abfolge der stärker entwickelten jungpleistozänen Böden jeweils annähernd vollständig ist, was eine sichere stratigraphische Korrelation über den ganzen Raum sehr erleichterte.

1) Untersuchungen zur vertikalen Gliederung der großen Lößprofile mit Rückschlüssen auf die paläogeographischen Verhältnisse des Pleistozäns begannen in Ungarn erst in den 30er Jahren mit dem Lößprofil von Paks, das bis zu Beginn der $60 \mathrm{er}$ Jahre das bevorzugte Studienobjekt blieb (Literaturübersicht s. BRONGER 1970). Erst in jüngster Zeit untersuchte vor allem PÉCSI (1964, 1965, 1966, 1971) eine Reihe weiterer Lößaufschlüsse. - Die großen Lößprofile im jugoslawischen Teil des Karpatenbeckens entlang der Donau und der Theiß wurden durch die Arbeiten von Laskarev (z. B. 1951) und besonders von Marković-Marjanović $(1954,1964,1969)$ bekannt. Jedoch sind in diesen und weiteren Arbeiten die Profile des gesamten Raumes mit dem Versuch einer stratigraphischen Korrelation und klimatischen Bewertung der einzelnen Löß-Paläoböden noch nicht mit Methoden, die wesentlich über den geomorphologischen Geländebefund hinausgehen, untersucht worden. 
Voraussetzung für eine Bodenstratigraphie ist ferner eine genetisch-typologische Ansprache der fossilen Böden, wodurch erst ihr sicherer Vergleich untereinander ermöglicht wird. Dazu sind oft Geländebeobachtungen allein nicht ausreichend. Denn für die Paläoböden muß betont werden, daß wesentliche diagnostische Merkmale, die bei r e z e n t e n Böden im Gelände erfaßbar sind, bei f os sil e n Böden verlorengingen, oder sekundär verändert wurden (s. u.). Deshalb erscheint das Studium der bodenbildenden Prozesse zur Aufhellung der Bodengenese um so notwendiger. Hierfür kommt der Bodenmikromorphologie eine besondere Bedeutung zu, da sie allein ein Gesamtbild der Bodenentwicklung, oft in ihren einzelnen Entwicklungsstadien (Polygenese, s.u.) vermittelt (vgl. auch Smolíková 1971). Zur Verdeutlichung seien einige Beispiele angeführt.

Häufig ist der A-Horizont eines fossilen Waldbodens ganz oder aber nur teilweise abgetragen; wieder einsetzende (geringe) Lößakkumulation und nachfolgende pedogene Überprägung, die bis auf den liegenden B-Horizont hinabgreifen kann, lassen einen sog. „Pedokomplex“ entstehen. Die genetische Ansprache des A-Horizontes oder der A-Horizonte ist auf makroskopischem Wege allein oft sehr unsicher. Kalkgehalts- und Korngrößenanalysen helfen auch nicht immer weiter. Zusätzliche mikromorphologische Untersuchungen können dagegen in den meisten Fällen die Aufeinanderfolge der bodenbildenden Prozesse und damit die polygenetische Entwicklung aufhellen. Andererseits gibt es gut erhaltene Löß-Braunerden wie auch Parabraunerden mit einem bis $\mathrm{zu} 50 \mathrm{~cm}$ mächtigen, nicht kolluvial bedingten A-Horizont. Hier konnte vor allem mikromorphologisch gezeigt werden, daß es sich um monogenetische Böden handelt, d. h. Ober- und Unterboden genetisch eine Einheit bilden (Beispiele s. Bronger 1966, 1969/70, 1970). Dazu kommt, daß besonders bei höherem Alter und größerer Mächtigkeit der Überlagerung von Paläoböden eine Gefügeverdichtung eintritt: aus einem ehemaligen Krümelgefüge kann so durch Reduzierung der Hohlräume ein mehr oder weniger stark verdichtetes Kohärentgefüge werden (BRONGER 1970). So ist es oft nur durch mikromorphologische Beobachtungen möglich, einen $f A_{1}$-Horizont einer Parabraunerde durch sein Eluvialgefüge von einem $f A_{h^{-}}$ Horizont einer Schwarzerde mit komprimiertem Feinschwammgefüge zu unterscheiden; makroskopisch sind die A-Horizonte durch Farbe und Gefüge kaum auseinanderzuhalten.

Weniger gut brauchbar als bisher allgemein angenommen ist das diagnostische Merkmal der Tonbeläge oder "coatings" als Anzeichen für eine Tonverlagerung. Durch diesen Prozeß wird bekanntlich die Braunerde vom Braunerde-Lessivé (Parabraunerde) unterschieden. Mikromorphologisch zeigt sich die Tonverlagerung in optisch orientiertem, d. h. doppelbrechendem Fließplasma oder Feintonplasma (Braunlehm-Teilplasma nach Kubiena 1956) besonders in den Leitbahnen, das sich vom geflockten Braunerdegrundgefüge scharf absetzt. Lediglich Orientierungsdoppelbrechung in Teilen des Bodengefüges bedeutet dagegen, daß keine nennenswerte Tonverlagerung im Zentimeter- oder gar Dezimeterbereich stattgefunden hat, dieser Boden genetisch also nicht als Braunerde-Lessivé angesprochen werden kann. Da schwache, makroskopisch sichtbare Tonwandbeläge ("coatings") wohl mit Orientierungsdoppelbrechung korrelieren können, $\mathrm{n}$ i c h t aber mit dem Vorhandensein von Fließplasma identisch sein $m$ ü s s e $n$, wird eine Unterscheidung von Braunerde und Braunerde-Lessivé (resten) am Aufschluß oft sehr erschwert, mikromorphologisch ist diese Unterscheidung jedoch sicher möglich. - Korngrößenanalysen, nicht selten für den „Nachweis“ einer Tonverlagerung herangezogen, geben für diesen Prozeß keine Beweise oder auch nur Belege.

Da die in Lößprofilen häufig zu findenden Tschernoseme rezent in einem weiten Klimabereich vorkommen, ist ihre Unterteilung in Subtypen wichtig. Denn nur für die Bildung und Erhaltung des (noch) primär carbonathaltigen Tschernosems ist ein echtes Steppen- bis Waldsteppenklima Voraussetzung (BRONGer 1973). Die Unterteilung der Tscher- 
noseme stützt sich u. a. auf die auch im Gelände ermittelbare Bodenreaktion ( $\mathrm{pH}-\mathrm{Wert}$ ), die jedoch durch die fast stets erfolgte sekundäre Carbonatinfiltration vom hangenden Löß bei fossilen Böden verfälscht und damit unbrauchbar wird. - Makroskopisch sichtbares Pseudomycel, das nach mikromorphologischen Untersuchungen in genetisch sehr verschiedenen Modifikationen vorkommt (BRONGer 1973), kann in Paläoböden sowohl vom liegenden wie vom hangenden Löß stammen, ebenso die von Regenwürmern ausgeschiedenen Calcite (Bronger 1970). Klastische Carbonate, vor allem in den Fraktionen 20-100 $\mu \mathrm{m}$, regellos in der Bodenmatrix bzw. im -skelett verteilt, sind demgegenüber als primär anzusehen.

Von wenigen Ausnahmen abgesehen wurden alle Paläoböden der auf Taf. I dargestellten Lößprofile im Karpatenbecken (dazu vergleichend fossile Böden aus bulgarischen, rumänischen, niederösterreichischen und südmährischen Lößprofilen) mikromorphologisch untersucht und so ihre genetisch-typologische Ansprache ermöglicht. Die Paläoböden sind an anderer Stelle (BRONGER 1973) nach ihren makro- und besonders mikromorphologischen Merkmalen dargestellt und genetisch-typologisch gedeutet.

Wie aus Taf. I ersichtlich, sind die Löß-Boden-Abfolgen des Alt- und Mittelpleistozäns im Vergleich zu denen des Jungpleistozäns seltener und höchstens mit einer Ausnahme sehr lückenhaft aufgeschlossen. Das gilt auch für den alt- und mittelpleistozänen Abschnitt des bekannten Lößprofils von Paks, das lange Zeit für eine komplette Serie des Pleistozäns gehalten wurde. In Stari Slankamen (gegenüber der Mündung der Theiß in die Donau) ist die Löß-Boden-Abfolge allerdings so vollständig wie nirgends sonst - vielleicht mit einer Ausnahme ${ }^{2}$ ) - im mittleren und östlichen Donauraum einschließlich Bulgariens und Rumäniens. Die Abfolgen von autochthonen Paläoböden der übrigen Lößprofile im Karpatenbecken stellen wahrscheinlich (Taf. I) nur Ausschnitte dieses Profils dar ${ }^{3}$ ). Basal liegen in Stari Slankamen, durch Löß bzw. Lößderivate getrennt, drei Böden $F_{11}, F_{10}$ und $\mathrm{F}_{9}$, von denen die beiden oberen stark gekappt sind. Sie sind alle drei als rubefizierte erdige Braunlehme anzusprechen. Darüber folgen zwei Braunerden $F_{8}$ und $F_{7}$, die gelegentlich typologisch zu den erdigen Braunlehmen überleiten. Abgeschlossen wird diese alt- und mittelpleistozäne Abfolge durch einen rubefizierten erdigen Braunlehm(-Lessivé) $\mathrm{F}_{6}$, der den drei basalen rubefizierten erdigen Braunlehmen $\mathrm{F}_{11}-\mathrm{F}_{9}$ im ganzen typologisch recht ähnlich ist. Wie diese hat auch der $\mathrm{F}_{6} \mathrm{zu}$ den Böden des Jungpleistozäns (und des Holozäns in diesem Gebiet) seiner Genese und Verwitterungsintensität (s. Kap. 3.1.) nach keine Analogie. Die Abfolge der Paläoböden $\mathrm{F}_{11}-\mathrm{F}_{6}$ unterscheidet sich typologisch wesentlich von den bisher bekannten alt- und mittelpleistozänen Löß-Boden-Abfolgen im westlichen Mitteleuropa, etwa in Südbaden oder Hessen (BRONGER 1966, 1969, 1969/70, Semmel 1974).

Wie eingangs schon erwähnt, sind die jungpleistozänen Löß-Boden-Abfolgen viel häufiger und vollständiger als die des Alt- und Mittelpleistozäns; für diesen Zeitabschnitt findet man so günstige Aufschlußverhältnisse nirgendwo sonst in Mitteleuropa. Zum anderen sind die jungpleistozänen Böden im Karpatenbecken - Tschernoseme, degradierte

2) Wahrscheinlich ist die alt- und mittelpleistozäne Löß-Boden-Abfolge in Červený kopec bei Brünn detaillierter gegliedert. Dabei erscheint die Rekonstruktion der stratigraphischen Verhältnisse infolge einer sehr komplizierten Verschachtelung von Lockerablagerungen problematisch, auch weil dieser Aufschluß eine einmalige Singularität unter den Lößprofilen der ČSSR darstellt. Kein Lößaufschluß in Mitteleuropa und im östlichen Donauraum enthält zahlenmäßig auch nur die Hälfte der alt- und mittelpleistozänen Böden, die KuKLA $(1961,1969)$ hier aussondern zu können glaubt.

3) Stratigraphische Parallelisierungsmöglichkeiten auf pedogenetischer Grundlage wurden an anderer Stelle näher diskutiert (BRonger 1973). - Im Einklang damit steht der kürzlich von PÉCSI und Pevzner (1974) mitgeteilte Befund, daß die Grenze zwischen der Brunhes- und Matuyama-Epoche im Löß unterhalb des hier als " $\mathrm{F}_{8}$ “ bezeichneten Bodens gefunden wurde. 
Tschernoseme, Tschernosem-Braunerden, Braunerden und Braunerde-Lessivés (Parabraunerden) - typologisch den rezenten Böden $\mathrm{d}$ i e s e s Raumes im ganzen recht ähnlich, dadurch auch untereinander gut vergleichbar. Die typologische Ähnlichkeit der jungpleistozänen mit den rezenten Lößböden gilt z. B. nicht für den nordwest-mitteleuropäischen Raum $\left.{ }^{4}\right)$. - Unter diesen günstigen Voraussetzungen war eine sichere stratigraphische Korrelation der Paläoboden-Abfolgen $\mathrm{F}_{5}$ bis $\mathrm{F}_{2}$ im Karpatenbecken möglich. In zwei Aufschlüssen, Basaharc und Mende, ist der $\mathrm{F}_{4}$ jeweils unterteilt in einen kräftig entwickelten $\mathrm{F}_{4 \mathrm{~b}}$ und einen schwach entwickelten $\mathrm{F}_{4 \mathrm{a}}$. Nur in Mende (Taf. I) liegt auf dem basalen Braunerde-Lessivé $F_{5 b}$ noch ein Tschernosem $F_{5 a}$, der mindestens teilweise als eine Neubildung aus frisch angewehtem carbonathaltigem Löß anzusehen und deshalb in den Beginn der Würm-Kaltzeit zu stellen ist (vgl. auch BRONGER 1970).

\subsection{Die bodenstratigraphische Fixierung des Riß/Würm-Inter- glazials.}

Für einen chronostratigraphischen Vergleich besonders mit jungpleistozänen Löß-Boden-Abfolgen in nordwestlich anschließenden Nachbargebieten und daraus folgend einer paläoklimatischen Auswertung ist zunächst die bodenstratigraphische Fixierung des Riß/ Würm-Interglazials als Beginn des Jungpleistozäns erforderlich. Eine Grundlage hierfür bietet der auf dem VI. INQUA-Kongreß in Warschau formulierte „stratigraphische Leitsatz “. Danach wurde der jüngste fossile ausgeprägte Waldboden im Riß/Würm-Interglazial gebildet. Dieser Leitsatz „gilt für alle Länder Mitteleuropas“ und „ist ganz besonders in den ungarischen Profilen zu beachten" (FINK 1962: 19, 20). Jedoch muß gefragt werden, ob z.B. auf Grund der hier hinzugewonnenen Erkenntnisse der stratigraphische Leitsatz für das Karpatenbecken noch seine so allgemeine Gültigkeit haben kann. Diese Problematik stellt sich nicht so sehr in den beiden Typuslokalitäten Dolní Věstonice und Stillfried, wo über dem als Riß/Würm-Interglazial anzusehenden Braunerde-Lessivé bzw. Braunerde(rest) lediglich degradierte Tschernoseme vorkommen. Dagegen findet sich im süd-östlichen Teil des Karpatenbeckens in zwei Lößprofilen (Vukovar und Mošorin/Titel) über dem $\mathrm{F}_{5}$, der ebenfalls als Bildung des Riß/Würm-Interglazials angesehen wird, bereits eine kräftig entwickelte Braunerde in der bodenstratigraphischen Position des $\mathrm{F}_{4}$. Deshalb kann der o.g. „stratigraphische Leitsatz“ hier keine entsprechende Anwendung finden. Seine Gültigkeit muß auf das Gebiet der beiden o.g. Typuslokalitäten und auf den südöstlich sich anschließenden NW-Teil des Karpatenbeckens reduziert werden.

Aus dieser Reduktion des "stratigraphischen Leitsatzes“ und aus bodengeographischen Überlegungen (Vergleich mit der Verbreitung der rezenten Böden) folgt, daß keiner der im Lößprofil von Basaharc aufgeschlossenen Böden - jeweils primär carbonathaltige Tschernoseme (Taf. I) dem Braunerde-Lessivé von Dolní Věstonice bodenstratigraphisch entsprechen kann. Im - unvollständigen - Profil von Nógrádveröce entspricht dieser Boden wahrscheinlich der basalen, intensiv verwitterten (Tschernosem)-Braunerde (Taf. I). Im Profil von Mende, wo die jungpleistozäne Löß-Boden-Abfolge am detailliertesten untergliedert ist (s. o.), kann der Braunerde-Lessivé von Dolní Věstonice erst dem Braunerde-Lessivé $F_{5 b}$ bodenstratigraphisch entsprechen, $d . h$. dieser Boden wurde im Riß/ Würm-Interglazial gebildet. Das gleiche gilt für den $\mathrm{F}_{5}$ in Paks. Die stratigraphischen $\mathrm{Pa}-$ rallelisierungen der Böden der übrigen Lößprofile des Karpatenbeckens sind in Taf. I zu-

4) Die Schwierigkeiten der bodentypologischen Einordnung (und damit der paläoklimatischen Ausdeutung) der Innerwürmböden insbesondere im nördlichen Mitteleuropa liegt daran, daß diese z. T. eingehend untersuchten Paläoböden (bes. Rohdensurg \& Meyer 1966) keine Analoga unter den rezenten Böden besitzen. Bezeichnungen wie „Brauner Verwitterungshorizont“", „Verbraunungszone", "Verlehmungszone", "Lamellenfleckenzone", "Humuszone" oder "Naßboden" machen dies deutlich. 
sammenfassend dargestellt, wobei der Boden jeweils unmittelbar unter der durchgezogenen Linie als Bildung des Riß/Würm-Interglazials angesehen wird.

Die wenigen bisher vorliegenden ${ }^{14} \mathrm{C}$-Daten stützen diese aus paläopedologischen Untersuchungen und bodengeographischen Überlegungen abgeleitete chronostratigraphische Gliederung der Löß-Boden-Abfolgen. Holzkohlenstücke an der Oberkante des $\mathrm{F}_{2}$ im Profil von Mende („Mende C“ nach PÉcsi 1965) ergaben ein Alter von $29800 \pm 600$ Jahren ${ }^{5}$ ) (PÉCSI 1966: 245). Ebenfalls Holzkohlestücke aus dem mittleren Teil des gleichen Bodens wurden auf ein ${ }^{14}$ C-Alter von 272001100 Jahren B.P. ${ }^{6}$ ) datiert (SEPpÄL ̈̈ 1971: 116). Der hier als $F_{3}$ bezeichnete Boden des Lößprofils von Batajnica zwischen Stari Slankamen und Belgrad (MARKović-Marjanović 1969, Bronger 1973) ergab ein ${ }^{14} \mathrm{C}$ Alter von ca. 36000 Jahren ${ }^{7}$ ). - Fossile Vertebraten wurden bisher in den Lößprofilen nur vereinzelt gefunden. Für die hier diskutierte Fragestellung soll der Fund von Elephas primigenius $^{8}$ ) direkt oberhalb des $\mathrm{F}_{5}$ in Paks nicht unerwähnt bleiben.

\section{Paläoklimatische Schlußfolgerungen}

3.1. Art und Ausmaß der Verwitterung der fossilen Böden im Vergleich zu den rezenten Böden im Karpatenbecken.

Für eine weitere Stützung der hier in aller Kürze abgeleiteten Löß-Boden-Stratigraphie sowie für daraus ableitbare Hinweise über die Klimageschichte des Pleistozäns sind zusätzliche Untersuchungen notwendig, die Aussagen über A r t und In t e n s i ä t der Verwit t e r ung gestatten.

Das wird um so deutlicher, wenn bodentypologische Bezeichnungen von rezenten Böden, dẹren Genese und klimatische Bildungsbedingungen bekannt sind, für fossile Böden in einem viel weiteren Sinne verwendet werden, wodurch eine mögliche paläoklimatische Ausdeutung sehr schwierig wird. Beispielsweise werden von HaAse, Lieberoth, Ruske et al. (1970: 148, 150) Braunerden, "die sowohl syn- als auch postsedimentär gebildet werden konnten" einerseits charakterisiert als "meist entkalkte Böden mit einer intensiven Verwitterung...". Sie werden von den o.g. Autoren in den Lößgebieten der DDR sowohl als Eem-Böden wie andererseits auch auf Alt- wie Mittelund Jungweichsellössen ausgeschieden. „Die Braunerden scheinen demzufolge unter verschiedenen klimatischen Bildungen entstanden zu sein." "Für die altweichselzeitliche Braunerde wurde schon immer ein kaltzeitliches Klima postuliert." - Gerade im Hinblick auf die Fragestellung, ob und wodurch Paläoböden als Klimazeugen herangezogen werden können, scheint es wenig nützlich, die mitteleuropäische Löß-Braunerde, die im Holozän bzw. im Eem-Interglazial gebildet wurde, mit kaltzeitlich gebildeten "Arctic brown soils" bzw. den Kryotagaböden Transbaikaliens und Jakutiens zu „Braunerden“ zusammenzufassen (HaAse, Lieberoth, Ruske et al. 1970: 150).

Auf Grund der großen Zahl fossiler „B $\mathrm{B}_{\mathrm{t}}$-Horizonte " in hessischen Lößprofilen - im Profil von $\mathrm{Bad}$ Soden/Taunus sind es acht über einem wahrscheinlich altpleistozänen Pseudogley - stellt SEMMEL (1967) die berechtigte Frage, ob dort jeder fossile $\mathrm{B}_{\mathrm{t}}$-Horizont als Rest einer warmzeitlichen Bodenbildung gedeutet werden kann. Die möglichen Folgerungen, entweder gebe es mehr Warmzeiten als früher angenommen wurde, oder jeder fossile $B_{t}$-Horizont könne nicht immer einer echten Warmzeit entsprechen, sind nach SEMmEL (1974) beide berechtigt. - Aus Tongehaltsschwankungen in den $\mathrm{B}_{\mathrm{t}}$-Horizonten "zwischen $27 \%$ und $35 \%$ " und aus einer gleichbleibenden qualitativen Tonmineralzusammensetzung in den Profilen von Bad Soden, Reinheim und Ostheim zu dem Schluß zu kommen, daß „stratigraphisch verwertbare Ergebnisse dabei nicht erzielt" wurden, ist allerdings nicht weiter verwunderlich. Absolute Ton g h a $1 \mathrm{te}$ lassen weder stratigra-

5) Bestimmung durch das geochemische Institut der Sowjet. Akademie d. Wiss. in Moskau (Lab.No. Mo 422), vgl. auch GEYH et al. 1969, dort weitere 14C-Daten von Funden bekannter Höhlen Ungarns.

6) Bestimmung durch das Isotopes, Inc., Westwood laboratories (USA), (Lab. No. I-3130, vgl. auch Radiocarbon 1969: 81).

7) Bestimmung ebenfalls in Moskau; freundl. mündl. Mitteilung von Frau Prof. Dr. Ivanova, Sept. 1972.

8) det. M. Kretzór, in PÉcsi \& Szebényi 1971: 28. 
phische Aussagen noch solche über das Ausmaß der Verwitterung zu, wenn nicht das Ausgangssubstrat gleicher ursprünglicher petrographischer Zusammensetzung $\mathrm{mit}$ in die $\mathrm{Unte} \mathrm{rsu}$ chungen e in bezogen wird. Daß quartäre Parabraunerden sich in ihrem qu a lit a ti v e n Tonmineralbestand sowohl untereinander wie auch beim Vergleich mit dem jeweiligen Ausgangslöß kaum oder nicht unterscheiden, ist schon früher dargelegt worden (BRONGER 1966, 1969/70, 1970, 1971). Nur Ergebnisse über das Ausmaß der pe d o che m is ch e n B ild ung einzelner Tonmineralarten in den Paläoböden im Vergleich zu den jeweiligen Ausgangslössen oder vollständige Verwitterungsbilanzen an sedimentär homogenen Bodenprofilen lassen im Vergleich zu entsprechenden Untersuchungen an rezenten Böden (Abb. 1 u. 2) paläoklimatische und stratigraphische Schlußfolgerungen zu.

Für die Frage nach Art und Intensität der Verwitterung scheiden - infolge der bereits eingangs erwähnten postpedogenen, z.T. diagenetischen Veränderung e n der Paläoböden - ein großer Teil der üblichen bodenchemischen Methoden aus: erwähnt wurden die sekundäre Aufkalkung der Böden, wodurch pH-Werte unbrauchbar werden, ferner sei der mit zunehmendem Alter der Böden fortschreitende Abbau der organischen Substanz erwähnt.

Weniger bekannt ist die offensichtlich postpedogene Veränderung nicht nur der röntgenamorphen, sondern auch der „pedogenen“ (dithionitlöslichen) Eisenoxide, die als „brauchbarer Maßstab für die Charakterisierung der lösungschemischen Verwitterung " gelten (Rohdenburg \& Meyer 1966). - Während bei re z e n t e n Tschernosemen im Vergleich $\mathrm{zu}$ Braunerden die unterschiedlich hohe Freisetzung des dithionitlöslichen Eisens $\left(\mathrm{Fe}_{\mathrm{d}}\right)$ die verschieden hohe pedochemische Tonbildungsrate, speziell das $\mathrm{A} \mathrm{u} \mathrm{s} \mathrm{ma} ß$ der lösungschemischen Schluffglimmer $\rightarrow$ Tonmineral-Umw a nd l u ng widerspiegelt, treffen diese Bezeichnungen für zahlreiche hierfür untersuchte fossile Böden aus mehreren großen Lößprofilen meist nur noch in eingeschränktem Maße oder garnicht mehr $\mathrm{zu}$, wobei die Korrelationen im allgemeinen mit höherem Alter immer weniger signifikant und schließlich nicht mehr gegeben sind (BRONGER 1974). Überlegungen, das pedogene Eisen (im Verhältnis zum Gesamteisen) als relatives Alterskriterium oder für paläoklimatische Schlußfolgerungen zu verwenden (BRUNNACKER 1970, HäDRICH 1970/71), können deshalb leider nicht zum Ziel führen.

Vor allem für palä okli mat is che Schlußfolgerungen bleibt nur der sehr zeitraubende Weg, die primären sowie die sekundären oder pedogenen Minerale, besonders die Tonminerale nach einzelnen Kornfraktionen getrennt zu untersuchen.

Für eine tonmineralogische Untersuchung ist es notwendig, die Tonfraktion $\langle 2 \mu \mathrm{m}$ weiter aufzuteilen. Dadurch wird einmal das Identifizieren erleichtert, weil einzelne Tonminerale im wesentlichen nur in einzelnen Teilfraktionen vorkommen, was dann eine relativ quantitative Auswertung sehr erleichtert (BRONGER 1966, 1969, 1969/70, 1970, 1971, 1973). Zum anderen haben Rohdenburg \& Meyer (1966) an innerwürmzeitlichen Böden in der Umgebung von Kassel festgestellt, daß die pedo $\mathrm{ch} \mathrm{e} \mathrm{m}$ is c he (Fein)Tonbildung in erheblichem Maße von einer $\mathrm{kryok}$ a s tischen Grobtonbildung der Fraktion 2-0,6 $\mu \mathrm{m}$ überlagert werden kann. Auch hierfür ist es notwendig, die Tonfraktion weiter in die Teilfraktionen $2-0,6 \mu \mathrm{m}, 0,6-0,2 \mu \mathrm{m}$ (Mittelton) und $\langle 0,2 \mu \mathrm{m}$ (Feinton) aufzuteilen. Leider sind diese Untersuchungen außerordentlich zeitauf wendig.

In den vergangenen Jahren wurde der Tonmineralbestand von alt-, mittel- und besonders jungpleistozänen Lößböden und, soweit möglich, vom Ausgangsmaterial der Profile von Nógrádveröce, Mende, Kulcs, Paks, Erdut und Stari Slankamen (Taf. I) untersucht, um Auskunft über Art und Ausmaß der kryoklastischen und/oder pedochemischen Tonbildung zu erhalten (Bronger 1970, 1971, 1973). Durch zusätzliche Korngrößenanalysen der Paläoböden der übrigen in Taf. I dargestellten Lößprofile ließ sich von den 
meisten Paläoböden die pedogene Tonbildung ermitteln $\left.{ }^{9}\right)$. Schließlich konnte im Rahmen des DFG-Schwerpunktprogrammes „Tonmineralogie“ von vier fossilen und zum Vergleich vier rezenten Böden, die nach mehreren Kriterien als sedimentär homogen gelten können, Mineralverwitterungsbilanzen erstellt werden. Sie sind in den Abb. 1 (A-D), Abb. 2 $(\mathrm{a}-\mathrm{d})$ und Abb. 3 (A-D), Abb. $4(\mathrm{a}-\mathrm{d})$ als Beispiele dargestellt. Einige der im Hinblick auf unsere Fragestellung wichtigsten Ergebnisse sollen im folgenden zusammengefaßt werden:

1a) Die pedogene Tonbildungsrate in den jungpleistozänen Tschernosemen (bis BraunerdeTschernosemen) $\mathrm{F}_{4}, \mathrm{~F}_{3}$ und $\mathrm{F}_{2}$ lag mit 8-12\% mindestens so hoch bzw. höher als in den rezenten Tschernosemen (i.w.S.) aus Löß im Karpatenbecken als auch anderer Löß-Tschernoseme Mitteleuropas (Beispiel s. Vergleich Abb. 1 A + B mit 3B, im einzelnen s. BRONGER 1973). Dazu muß berücksichtigt werden, daß die jungpleistozänen Tschernoseme im nördlichen Karpatenbecken bei annähernd vollständiger Erhaltung mindestens ebenso mächtig, im südlichen Teil nach Süden zunehmend bis doppelt so mächtig werden (Taf. I). - Die Tonbildungsrate der Tschernosem-Braunerden $\mathrm{F}_{3}$ und/oder $\mathrm{F}_{4}$ lag mit 8,5-13\% nur wenig über der der Tschernoseme (i.w.S.).

b) Demgegenüber war die pedogene Tonbildung in den letztinterglazialen Braunerden $\mathrm{F}_{5}$ mit 16-19,5\% wesentlich höher als in den hangenden Tschernosemen bis Tschernosem-Braunerden $\mathrm{F}_{4}$ bis $\mathrm{F}_{2}$, wobei eine nennenswerte Tonverlagerung in keinem Fall in Betracht kommt. Sie liegt auch noch höher als die der rezenten Braunerden von Somogyvár und Banovo Brdo, obwohl die Ausgangssubstrate der letzteren deutlich höhere Glimmergehalte (vgl. Abb. 2c+d mit 4c), speziell höhere Anteile der besonders verwitterungsanfälligen Biotite aufweisen als die letztinterglaziale Braunerde $\mathrm{F}_{5}$ von Stari Slankamen. - Dazu kommt, daß die noch erhaltenen $\mathrm{B}_{\mathrm{v}}$-Horizonte der jungpleistozänen Braunerden etwa doppelt so mächtig, die der mittelpleistozänen $\left(\mathrm{F}_{7}, \mathrm{~F}_{8}\right)$ mehr als doppelt so mächtig sein können wie die $\mathrm{B}_{\mathrm{v}}-$ Horizonte der rezenten Braunerden.

c) Im Vergleich zu den Braunerden ist der Grad der Verlehmung im mittelpleistozänen erdigen Braunlehm-(Lessivé) $\mathrm{F}_{6}$ von Stari Slankamen mit über 28\% erheblich höher als der der mittel- und jungpleistozänen Braunerden (Abb. $3 \mathrm{D}$ ), wobei die Tonverlagerung nur eine sehr geringe Rolle gespielt hat. Auch die Tonbildungsrate der beiden unteren Braunlehmreste $F_{10}$ und $F_{9}$ in Stari Slankamen ist immer noch höher als die - der mit 19,5\% schon hohen - des $\mathrm{F}_{5}$ (Abb. $3 \mathrm{C}$ ), obwohl der Tonmineralbestand des $\mathrm{F}_{\mathbf{1 0}}$ bzw. des $\mathrm{F}_{\mathbf{9}}$ jeweils nur mit dem eines pedogenen überprägten „Lösses“, der noch Material vom hangenden Unterboden enthält, verglichen werden kann (Taf. I).

2) Die pedogene Tonbildung drückt sich bei allen Böden zum größten bis allergrößten Teil, bei manchen Böden sogar ausschließlich in einer Zunahme der Feintonfraktion $\langle 0,2 \mu \mathrm{m}$ aus. Dabei ist die sehr starke Zunahme der Feintonanteile in den Braunlehmen besonders auffallend. - Selbst im Löß-Syrosem $F_{1}$ von Erdut, in dem so gut wie keine Mineralverwitterung (Abb.4a), auch keine nennenswerte Verschiebung der Mineralarten-Korngrößenspektren stattgefunden hat (Abb. $3 \mathrm{~A}$ ), ist lediglich eine geringe Zunahme der Feintonanteile zu beobachten.

9) Dabei müssen diejenigen Böden unberücksichtigt bleiben, deren Ausgangssubstrat auf Grund ihrer Korngrößenzusammensetzung als ursprünglich sedimentär inhomogen anzusehen ist. Das ist z. B. der Fall beim unteren degradierten Tschernosem des „PK II“ und dem des „PK III“ im Profil von Unter-Wisternitz. 
3) Auf Grund der stets nur geringen bis fehlenden pedogenen Grob- und auch Mitteltonbildung (s. o.), dazu der minimalen Anteile von Feldspäten in diesen Fraktionen (wie auch in den vier Beispielen im Feinschluff (Abb. 3 A-D) kann weder in den würmzeitlichen Tschernosemen noch in den jung- und mittelpleistozänen Braunerden und auch nicht in den mittel- und altpleistozänen Braunlehmen eine signifikante, durch Frostverwitterung erklärbare Tonmineralbildung in der Fraktion 2-0,6 $\mu \mathrm{m}$ abgeleitet werden, speziell auch keine Anreicherung von Feldspäten im Grobton. Das gilt selbst für den mindestens teilweise synsedimentär entstandenen Löß-Syrosem $F_{1}$ von Erdut, für den - nach den Ergebnissen von Rohdenburg \& Meyer (1966) an Böden gleicher, jungwürm(weichsel)zeitlicher Entstehungsperiode im Raume Kassel die Möglichkeit für einen progressiven kyroklastischen Mechanismus vorwiegend der Grobtonbildung besonders günstig schienen. Folglich dürfte die Tonmineralentstehung allein durch pedo $\mathrm{ch}$ e $\mathrm{m}$ is $\mathrm{che}$ Umbildung und Neubildung erfolgt sein.

4a) Bei der pedochemischen Entstehung und Umwandlung der Tonminerale entfällt sowohl bei den Tschernosemen wie bei den Braunerden und auch bei den erdigen Braunlehmen der weitaus größte Teil auf die Bildung von Illit e n mit ca. $25-40 \%$ und besonders von Montm orillon it e n mit ca. 45-60\% (Beispiele s. Abb. 4 a-d). - Die pedochemische Illit- und besonders Montmorillonitbildung ist in den Braunerden (i.e.S.) stets deutlich höher als in den Tschernosemen (i.w.S.), in den Braunlehmen - soweit feststellbar - noch deutlich höher als in den Braunerden.

b) Bemerkenswert ist schließlich die sehr geringe Kaolinitbildung auch in den $\mathrm{Bra} \mathrm{a}^{\circ} \mathrm{ulehmen}$, obwohl z. B. im $\mathrm{F}_{6}$ von Stari Slankamen eine starke Feldspatverwitterung festgestellt wurde, die über $40 \%$ der vorhandenen Vorräte ca. 8 Gewichtsprozente des gesamten Mineralbestandes! - aufgezehrt hat (Abb. 3 $\mathrm{D}+4 \mathrm{~d})$. Auch in den mengenmäßig stark dominierenden Feintonfraktionen der altpleistozänen Braunlehme, in denen sich (s. o.) zum allergrößten Teil die Endprodukte der pedochemischen Verwitterung finden, sind Kaolinite aufgrund relativ schwacher 7,2 §-Interferenzen nur zu $<5 \%$ enthalten, gegenüber ca. $80 \%$ an Montmorilloniten. In dem besonders intensiv ausgeprägten rubefizierten erdigen Braunlehm in Kulcs an der Plio-Pleistozängrenze (Taf. I) sind in der mengenmäßig ebenfalls stark dominierenden Feintonfraktion überhaupt keine Kaolinite enthalten (BRONGER 1973).

Diese Befunde widerlegen das Postulat von Pécsi (in Pécsi \& Szebényi 1971: 10), wonach „an einigen Stellen an der Basis von mächtigeren Lößabfolgen rote Tonböden, insbesondere kaolinitische rote Tone, angetroffen werden (Fig. 4)", wobei damit gerade auf den basalen Boden von Kulcs („Kulcs red clay“) hingewiesen wird.

Primärminerale $>2 \mu$

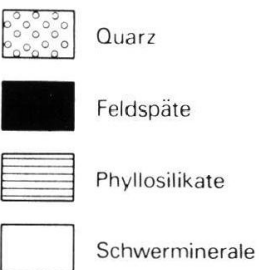

Tonminerale $<2 \mu$

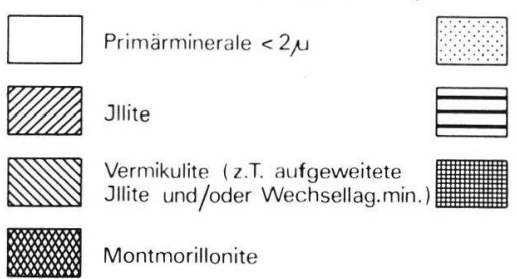

Kaolinite

Chlorite

Kaolinite,Chlorite, Vermikulite ev. Montmorillonite (in der Grob-u. Mitteltonfraktion meistens nicht weiter unterteilt )

Signaturen zu den Abb. 1-4. 


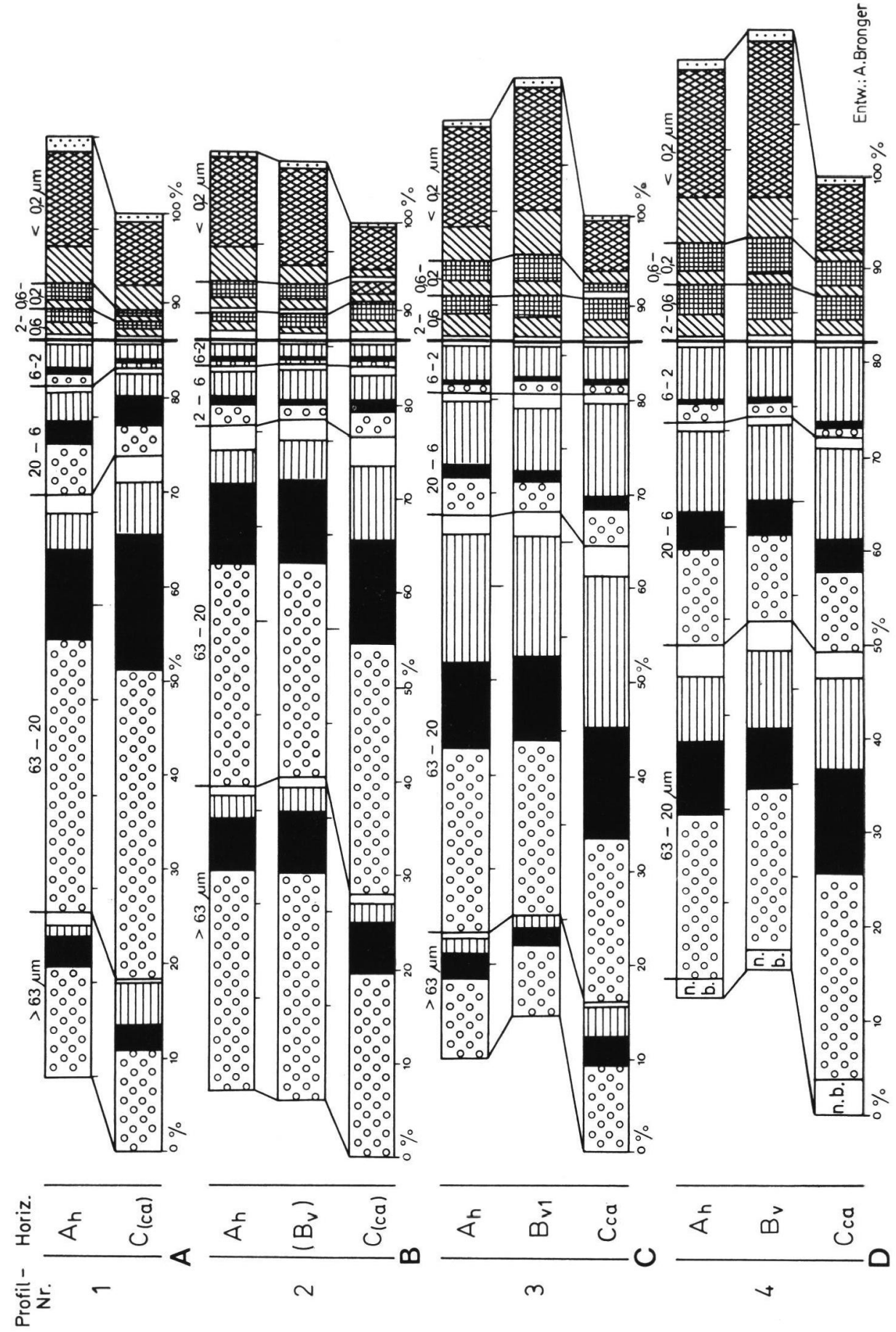

Abb. 1. (A-D). Mineralzusammensetzung von 4 r e z e n t e n Lößböden (Feinsand-, Schluff- und Tonfraktionen). 

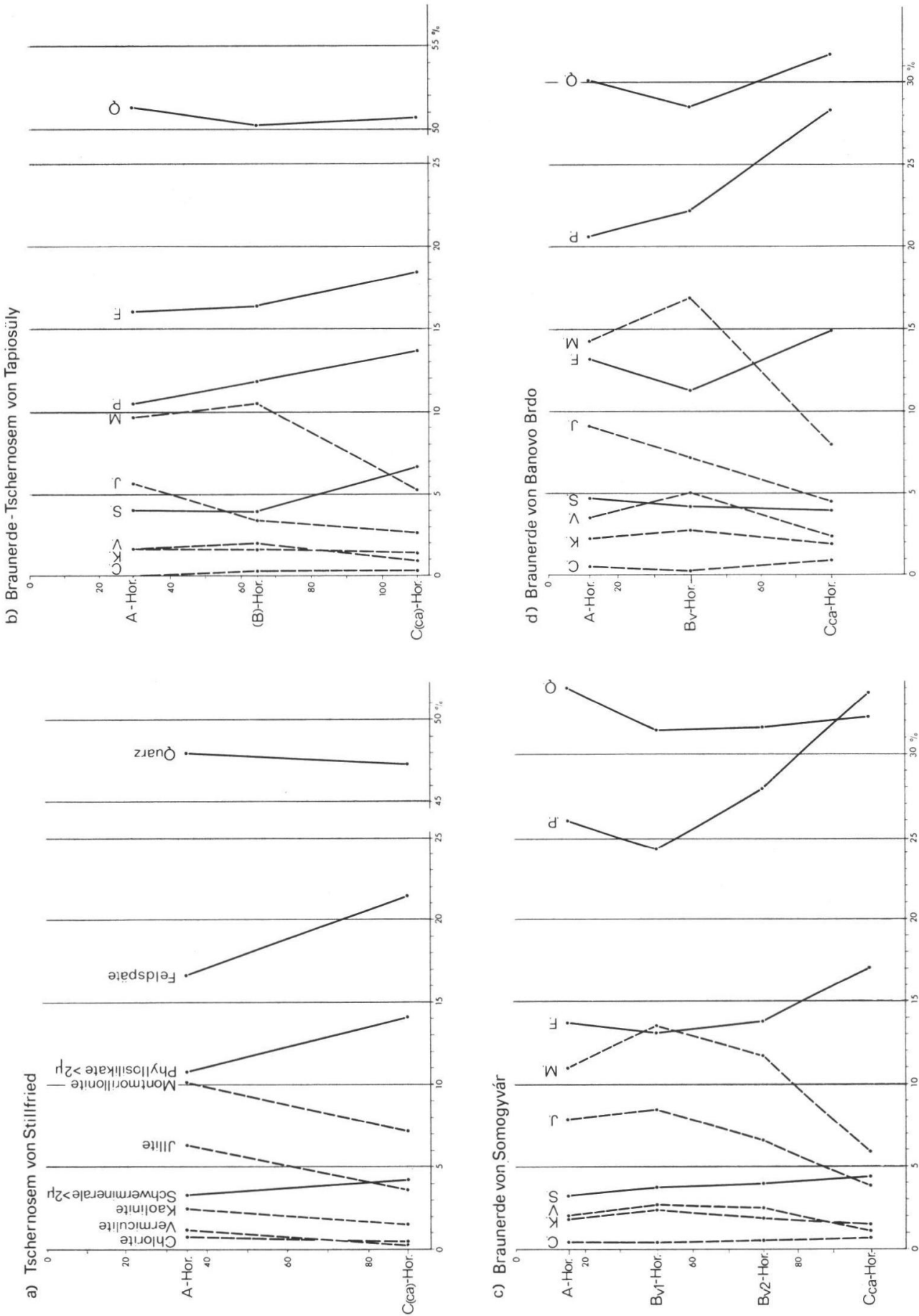

Abb. 2. (a-d). Mineralzusammensetzung der 4 rezenten in Abb. 1 dargestellten Lößböden (Summenkurven). 


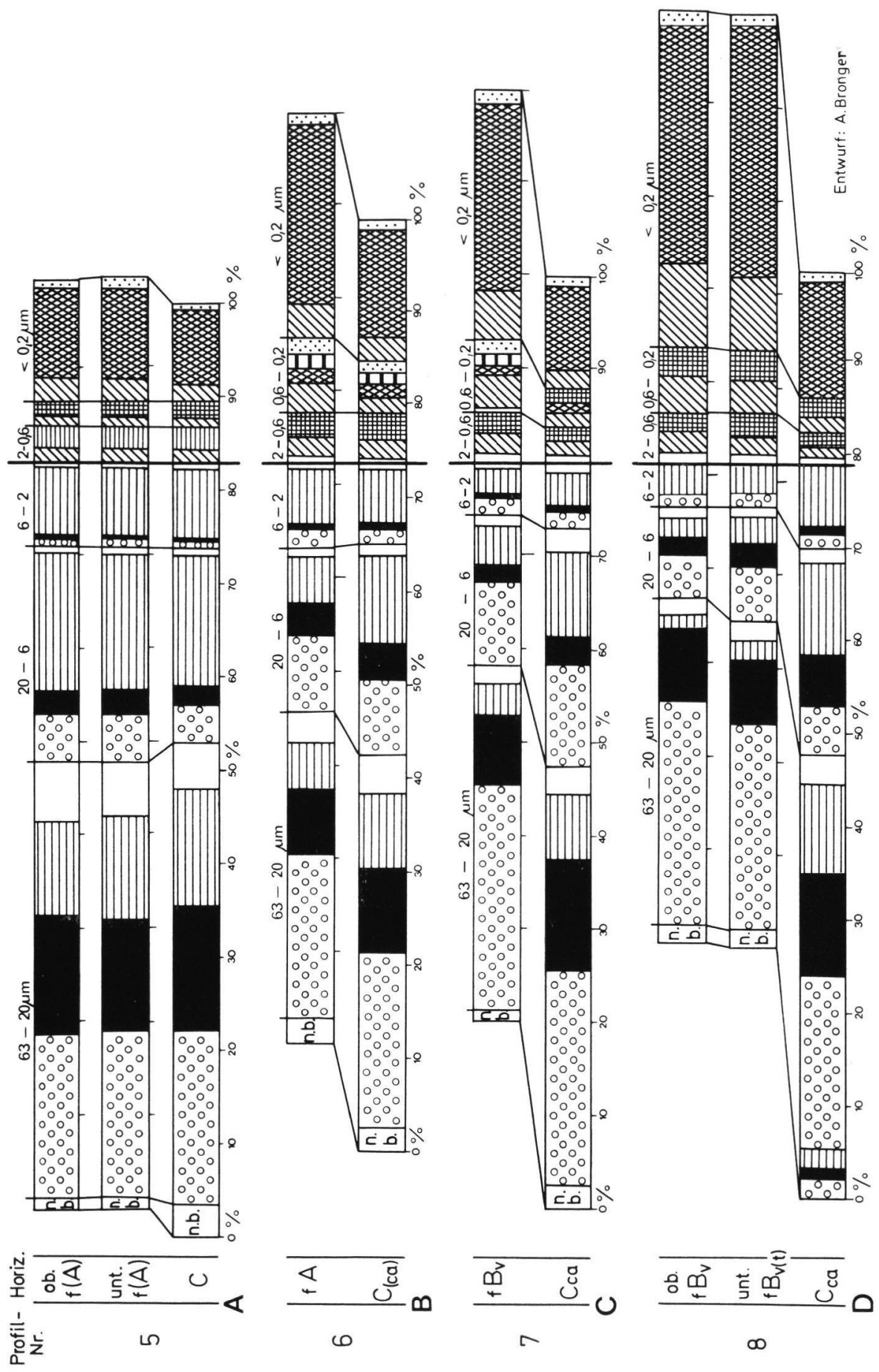

Abb. 3. (A-D). Mineralzusammensetzung von 4 fossile n Lößböden (Schluffund Tonfraktionen). 

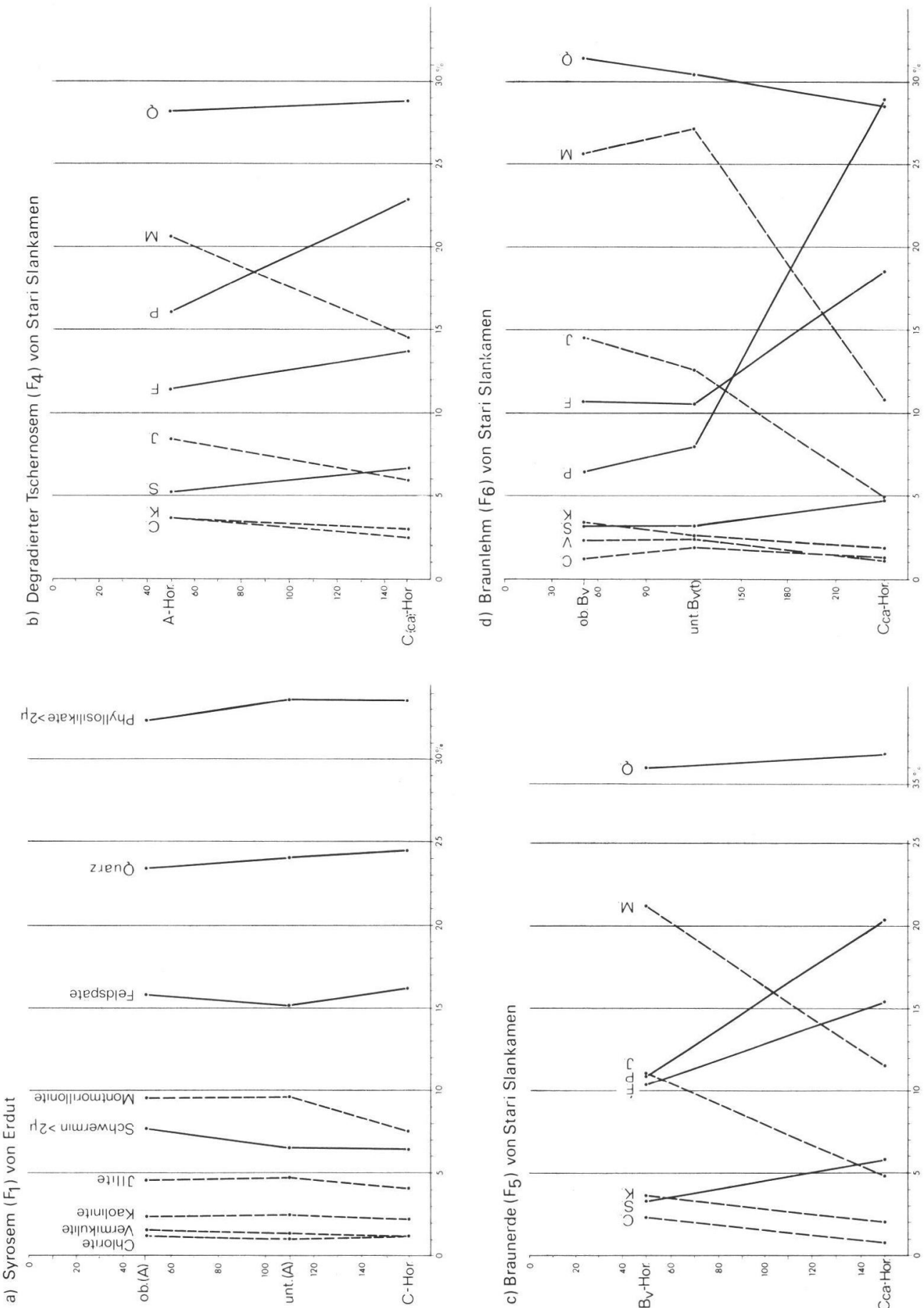

o

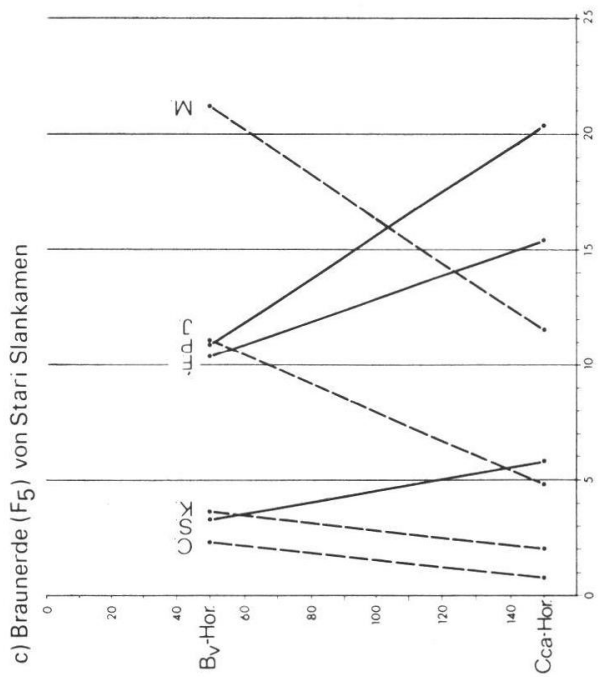

Abb. 4 (a-d). Mineralzusammensetzung der 4 fossilen in Abb. 3 dargestellten Lößböden (Summenkurven). 


\subsection{Zur Klimaentwicklung im Alt- und Mittelpleistozän}

Die Grundlage für die Beantwortung dieser Fragestellung bilden in erster Linie die paläpedogenetischen und (ton)mineralogischen Untersuchungsergebnisse der basalen LößBoden-Abfolge des Profils von Stari Slankamen. Wahrscheinlich stellen die Abfolgen von autochthonen Paläoböden der übrigen Lößprofile im Karpatenbecken nur Ausschnitte dieses Profils dar (Bronger 1973). Auch von den bisher bekannten Lößprofilen des östlichen Donauraumes (Conea 1970, Fotakiewa 1970) ist keines für den Zeitraum des Alt- und Mittelpleistozäns so detailliert gegliedert (vgl. Kap. 2.1.).

Für eine paläoklimatische Ausdeutung ergeben sich Schwierigkeiten einmal dadurch, daß besonders die altpleistozänen Böden meist stark gekappt sind und dicht übereinanderliegen (Taf. I), ferner daß rezente Analoga zu den rubefizierten erdigen Braunlehmen des Alt- und Mittelpleistozäns aus Löß bzw. lößähnlichen Sedimenten bisher nicht bekannt sind. Jedoch kann wahrscheinlich gemacht werden, daß die rubefizierten erdigen Braunlehme des Alt- und Mittelpleistozäns auf Grund des im wesentlichen gleichen Verwitterungstyps - gleiche A r t der pedochemischen Tonmineralbildung und -umwandlung bei höchstens geringer Quarzverwitterung, lediglich wesentlich höherer Verwitterungsintensität - wahrscheinlich Weiterbildungen von Braunerden sind. Das wird zusätzlich belegt durch die mikromorphologischen Untersuchungsergebnisse, wonach in diesem Zeitraum Übergänge zwischen beiden Bodentypen in Form von z. T. bereits deutlich rubefizierten Braunlehm-Braunerden vorkommen (Taf. I). Damit soll jedoch nicht gesagt sein, daß allein der Faktor Zeit für die (Weiter)Bildung von erdigen Braunlehmen verantwortlich war. Auch unterschiedliche Klimate müssen eine wesentliche Rolle gespielt haben. - Vorteilhaft für die paläoklimatische Ausdeutung ist, daß die Böden auch dieses Zeitabschnittes - Braunerden wie Braunlehme - im ganzen aus relativ einheitlichem Ausgangsmaterial entstanden sind. Schließlich darf angenommen werden, daß sich die Böden im allgemeinen innerhalb e in e $r$ Warmzeit gebildet haben, wenn auch nicht ausgeschlossen werden soll, daß der eine oder andere Boden das Produkt vielleicht mehr als einer Warmzeit sein könnte.

Die Ursachen, weshalb es in diesem Zeitabschnitt - im Gegensatz zum Jungquartär vor allem zur Bildung von rubefizierten erdigen Braunlehmen neben Braunerden kam, dürfte weniger an möglicher längerer Dauer als an anderen Klimabedingungen liegen. Diese Böden entsprechen der "subtropischen Bodenprovinz" Kubienas (1964). Ihre Bildung setzt höhere Temperaturen und größere Durchfeuchtung bei wechselfeuchtem Klima voraus, was neben bedeutend stärkerer Silikatverwitterung und Tonmineralbildung zur Rubefizierung führte (nähere Diskussion zur Rubefizierung s. BRONGER 1973). Zur Entstehungszeit der drei alt- $\left(\mathrm{F}_{11}-\mathrm{F}_{9}\right)$ und des mittelpleistozänen Braunlehms $\left(\mathrm{F}_{6}\right)$ muß die mediterrane Klimakomponente wesentlich stärker als im letzten Interglazial (Kap. 3.3.) und im Holozän ${ }^{10}$ ) gewesen sein.

Bereits im unteren Pannon war nach ungarischen floristischen Arbeiten (ANDREÁNSKY \& Kovács 1955) das Klima zwar noch subtropisch feuchter (ca. $1300 \mathrm{~mm}$ Jahresniederschlag), aber nicht viel wärmer als heute, mit einer Jahresmitteltemperatur von fast $15^{\circ} \mathrm{C}$ (heute $10-11^{\circ} \mathrm{C}$ ). Ahnliche Temperaturen herrschten auch noch im Oberpannon bei fast $15^{\circ} \mathrm{C}$ mittlerer Jahrestemperatur, mit ca. $6,5^{\circ} \mathrm{C}$ im kältesten Monat, ca. $22,5^{\circ} \mathrm{C}$ im wärmsten Monat ${ }^{11}$ ); die Jahresniederschläge waren auf ca. $1150 \mathrm{~mm}$ zurückgegangen ${ }^{11}$ ). Ins-

10) Auch für das augenblickliche Klima Ungarns betont ZóLyomi (1958) einen bedeutenden submediterranen Klimaeinfluß, der im Atlantikum wahrscheinlich noch stärker war.

11) Heute beträgt im inneren Teil des Karpatenbeckens die Temperatur des kältesten Monats -1 bis $-2,5^{\circ} \mathrm{C}$, die Jahresniederschläge $510-620$ (650) $\mathrm{mm}$ für die Tschernosem-, bis etwa $720-740 \mathrm{~mm}$ für die Löß-Braunerde- und darüber für die Braunerde-Lessivé-Gebiete (s. KlimaAtlas v. Ungarn Bd. II, 1967; vgl. auch Bronger 1973). 
gesamt wird das Klima des Oberpannons als „ausgeglichen, feucht, an der Grenze der subtropischen und gemäßigten Zone" bezeichnet (ANDREÁNSKY \& Kovács 1955: 14, 15). Leider sind oberpliozäne (levantinische) und unterpleistozäne Floren nicht bekannt, es „fehlt eine Verbindung zwischen den Tertiärfloren und der gegenwärtigen" (ANDREÁNSKY \& Kovács 1955: 256). - Daraus darf mit großer Wahrscheinlichkeit gefolgert werden, daß auch in den altpleistozänen Warmzeiten, in denen sich die rubefizierten erdigen Braunlehme bildeten, das Klima nicht oder kaum wärmer und feuchter als im Oberpannon war, also ein wechselfeucht-subtropisches (mediterranes) Klima nahe dem Übergang zur gemäßigten Zone angenommen werden kann.

Zusammengefaßt lassen sich für die hier als Alt- und Mittelpleistozän bezeichneten Abschnitte zunächst drei Warmzeiten unterscheiden, in denen die mediterrane Klimakomponente sehr stark, wenn nicht dominierend gewesen sein muß. Mindestens die älteste Warmzeit umfaßt einen ganz erheblich längeren Zeitraum als das Holozän. Diese drei Warmzeiten wurden jeweils von "Lößkaltzeiten“ unterbrochen, die möglicherweise von kurzer Dauer waren. - Im mittleren Abschnitt des Pleistozäns werden die „Lößkaltzeiten" durch zwei Warmzeiten unterbrochen, in denen es zur Ausbildung von Braunerden kam, die gelegentlich typologisch zu den erdigen Braunlehmen überleiten, jedoch schwächer verwittert und kaum rubefiziert sind. Wo die $\mathrm{B}_{\mathrm{V}}$-Horizonte noch weitgehend erhalten blieben, wie z. B. in Paks, ist ihre Mächtigkeit bis zu 21/2 mal so groß wie bei rezenten Löß-Braunerden, bei vergleichsweise höherer Tonbildungsrate (BRONGER 1970). In diesen Warmzeiten war der mediterrane Klimaeinfluß aller Wahrscheinlichkeit nach noch deutlich stärker als im letzten Interglazial (Kap. 3.3.) und im Holozän; die Bildung der Braunerden bis Braunlehm-Braunerden umfaßte einen erheblich längeren Zeitraum als die des Holozäns. - Das Mittelpleistozän wird in den Lößprofilen des Karpatenbeckens abgeschlossen durch einen rubefizierten erdigen Braunlehm-(Lessivé) $\mathrm{F}_{\mathbf{6}}$, der im ganzen typologisch den drei basalen rubefizierten erdigen Braunlehmen recht ähnlich ist. Auch hier hat ein Klima mit einer sehr starken, wenn nicht dominierenden mediterranen Komponente geherrscht, und die Dauer der Warmzeit muß wesentlich länger gewesen sein als die des Holozäns.

Sicherlich ist auch in Stari Slankamen die alt- und mittelpleistozäne Löß-Boden-Abfolge nicht vollständig. Aber selbst wenn sie nur wenige Lücken aufweisen würde, so folgt aus der vergleichenden Betrachtung der alt- und mittelpleistozänen Bodenabfolgen in den übrigen Lößprofilen des Karpatenbeckens (Taf. I), daß die Abtragungsprozesse einmal im Altpleistozän, sodann im oberen Mittelpleistozän besonders stark gewesen sein müssen. Denn die drei basalen rubefizierten erdigen Braunlehme $F_{11}-F_{9}$ von Stari Slankamen finden sich weder im Profil von Mošorin/Titel, noch im Profil von Neštin und auch nicht in Paks, vom "roten Tonboden" in der dortigen Bohrung abgesehen. Lediglich in Kulcs (Taf. I, und möglicherweise in Dunaföldvár) ist ein möglicherweise dem $F_{11}$ entsprechender Boden(rest) noch erhalten. Der mittelpleistozäne rubefizierte erdige Braunlehm(Lessivé) $\mathrm{F}_{6}$ fehlt gleichfalls in Paks, ebenso in Erdut und aller Wahrscheinlichkeit nach in Mošorin/Titel, abgesehen von den großen Profilen, die nur jungpleistozäne Löß-BodenAbfolgen enthalten wie Basaharc, Nógrádveröce, Mende und Vukovar (Taf. I). Deshalb müssen auch in der Kaltzeit - vielleicht mehreren Kalt- (und Warm)zeiten - zwischen der Bildung des $\mathrm{F}_{6}$ und des Riß/Würm-interglazialen $\mathrm{F}_{5}$ die Abtragungsprozesse dominierend gewesen sein. - Der hier aus paläopedologischen Untersuchungen abgeleitete Versuch einer zeitlichen Einordnung der rhythmischen Morphodynamik am Rande des inneren Karpatenbeckens läßt auffallende Parallelen zwischen den Rhythmen der Sedimentationsfolgen und den tektonischen Hebungsphasen der umgebenden ungarischen Mittelgebirge (Kretzói \& Krolopp 1972) erkennen. Das wurde an anderer Stelle (Bronger 1973) näher ausgeführt. 
Abschließend sei hervorgehoben, daß die alt- und mittelpleistozäne Klimaentwicklung in diesem Teil Mitteleuropas wesentlich anders verlief als z. B. in der südlichen Oberrheinebene. Dort kam es im etwa entsprechenden Zeitabschnitt zur Bildung von 4-5 Braunerde-Lessivés, deren jeweilige Verwitterungsintensität, gekennzeichnet durch die pedochemische Tonbildungsrate, der des rezenten Braunerde-Lessivés aus Löß vergleichbar ist (Bronger 1966, 1969, 1969/70), woraus folgt, daß das Klima der Warmzeiten dort stets etwa dem heutigen entsprach. Aus der größeren Mächtigkeit der Löß-Paläoböden kann lediglich auf eine längere Dauer der jeweiligen Warmzeiten gegenüber dem Holozän geschlossen werden.

\subsection{Zur Klimaentwicklung des Jung pleistozäns}

Wie schon mehrfach hervorgehoben, sind die jungpleistozänen Löß-Boden-Abfolgen viel häufiger und vollständiger als die des Alt- und Mittelpleistozäns aufgeschlossen. Die typologische Ähnlichkeit der meisten jungpleistozänen mit den rezenten Böden dieses Raumes, dazu der günstige Umstand, daß es sich nur um klimaphytomorphe Böden handelt, macht eine paläoklimatische Auswertung für diesen Zeitabschnitt auf einer wesentlich besser gesicherten Grundlage möglich. Art und Ausmaß der Silikatverwitterung, vor allem der pedochemischen Bildung und Umwandlung von Dreischicht-Tonmineralen in den drei Tonteilfraktionen der Paläoböden im Vergleich zum Ausgangsmaterial (Kap. 3.1.) erlauben genauere Aussagen über die Intensität der Verwitterung. Die vergleichende Gegenüberstellung mit dem Verwitterungsgrad rezenter Böden gleichen Typs ermöglicht weitere Rückschlüsse auf das jeweilige Bildungsklima der Paläoböden.

Die paläoklimatischen Schlüsse aus diesen Untersuchungsergebnissen lassen sich bei vorsichtiger Auswertung wie folgt zusammenfassen:

1. Auch im inneren trockeneren Teil des Karpatenbeckens kam es im Riß/Würm-Interglazial auf den grundwasserfernen Lößstandorten zur Ausbildung einer typischen Braunerde $\mathrm{F}_{5}$. Da hier im Holozän primär carbonathaltige Tschernoseme bis Braunerde-Tschernoseme entstanden (näheres s. BRONGER 1973), muß gefolgert werden, daß das Klima im Karpatenbecken einschließlich der nordwestlich angrenzenden Nachbargebiete feuchter (und wahrscheinlich ozeanischer) gewesen ist. Jedenfalls im inneren Teil des Karpatenbeckens war es andererseits nicht so feucht, daß es - trotz höherer pedochemischer Tonbildung im Vergleich zur rezenten Löß-Braunerde - zur Bildung eines ausgeprägten Braunerde-Lessivés kommen konnte. Die bis doppelt so große Mächtigkeit der - meist nicht mehr vollständig erhaltenen $-\mathrm{B}_{\mathrm{v}}$-Horizonte der Riß/ Würm-interglazialen gegenüber denjenigen der rezenten Braunerden ist höchstwahrscheinlich in erster Linie durch eine längere Dauer, weniger durch deutlich höhere Temperaturen bedingt. Auch für die grundwasserfernen Lößstandorte im inneren trockenen Teil des Karpatenbeckens mit heute Waldsteppen- bis Löß-Strauchsteppenvegetation (Zólyomi 1967) darf in den mittleren warmen Phasen des Riß/Würm-Interglazials ein Eichenmischwald angenommen werden, ähnlich wie heute in den Braunerdegebieten des Somogyer Hügellandes und der Baranya, vielleicht mit etwas stärkerer mediterraner Komponente (Kretzór \& Vértes 1965, Zólyomi 1967). Diese Aussage gewinnt dadurch an Wahrscheinlichkeit, daß die Löß-Braunerde in einem im Vergleich $\mathrm{zu}$ den Tschernosemen (i.e.S.) klimatisch anscheinend eng begrenzten Gebiet vorkommt (BRONGER 1973, vgl. auch Fußnote ${ }^{11}$ ).

2. Auch die innerwürmzeitlichen T'schernoseme und Braunerde-Tschernoseme $F_{4}, F_{3}$ und $\mathrm{F}_{2}$ zeigen einen mindestens so hohen Verwitterungsgrad wie die rezenten Böden gleichen Typs in diesem Gebiet, ausgedrückt u.a. durch eine mindestens so hohe, in vielen 
Fällen höhere pedochemische Tonbildungsrate. Dabei ist zu berücksichtigen, daß in keinem der dafür untersuchten Böden eine signifikante, durch Frostverwitterung erklärbare Tonmineralbildung stattfand (Kap. 3.1.). Hinzu kommt, daß die jungpleistozänen Tschernoseme im nördlichen Teil des Karpatenbeckens bei annähernd vollständiger Erhaltung mindestens ebenso mächtig, im südlichen Teil nach Süden zunehmend bis doppelt so mächtig werden.

Aus diesen Untersuchungsergebnissen muß gefolgert werden, daß die drei In $\mathrm{n}$ erw ürmböden dieses $\mathrm{R}$ a umes $\left(\mathrm{F}_{4}, \mathrm{~F}_{3}\right.$ und $\left.\mathrm{F}_{2}\right)$ nicht Zeugen eines Interstadialklimas, sondern e in es warm ze it 1 ichen $\mathrm{Kl}$ imas ${ }^{12}$ ), im ganzen etwa vergleichbar dem heutigen, gewesen sein müssen.

Bei näherer Betrachtung der stratigraphisch aequivalenten Böden sind weitere Schlußfolgerungen möglich:

a) Mit Ausnahme der Lokalitäten Basaharc und Mende hat der $F_{4}$ zwischen Dolní Věstonice und Stari Slankamen stets das Stadium des degradierten, d. h. carbonatfreien Tschernosems bis einer Tschernosem-Braunerde, in zwei Profilen - Mošorin/ Titel und Vukovar - sogar das der Braunerde erreicht (Taf. I). Da auch die Tschernoseme aus Löß an der Grenze ihrer Verbreitung zur feuchten Seite in einem klimatisch anscheinend eng begrenzten Raum vorkommen (s. Fußnote 11; BRONGER 1973), darf daraus gefolgert werden, daß das Klima z. Z. der Bildung des $\mathrm{F}_{4}$-Bodens dem heutigen recht ähnlich gewesen sein muß. Da dieser Boden bei einigermaßen vollständiger Erhaltung mindestens so mächtig, meistens mächtiger als der rezente Boden gleichen Typs ist, bei gleichem Grad der pedochemischen Verwitterung (s. o.), darf weiter gefolgert werden, daß für die Bildung dieses Bodens bei vorsichtiger Schätzung mindestens 5000 Jahre notwendig waren (s. u. Punkt 2b), selbst bei Berücksichtigung der Möglichkeit, daß die größere Mächtigkeit durch ein etwas kontinentaleres Klima und damit größerem Tiefgang der Bioturbation (s. u.) mitbedingt sein könnte. In dieser Zeit dürfte in den Plakorlagen des Karpatenbeckens ähnlich wie heute (Zólyomi 1967) im allgemeinen eine Waldsteppe, in dafür günstigen Gebieten ein Eichenmischwald verbreitet gewesen sein, vielleicht mit geringerer mediterraner und etwas stärkerer kontinentaler Komponente.

b) Demgegenüber ist der $\mathrm{F}_{3}$ und der $\mathrm{F}_{2}$ meistens als noch primär carbonathaltiger Tschernosem, seltener als degradierter Tschernosem bzw. als Ubbergang zwischen Tschernosem und Braunerde ausgebildet. Im Vergleich zu den zuletzt genannten Subtypen ist die Bildung des (noch) primär carbonathaltigen Tschernosems in einem klimatisch weite-

12) Leider sind die Begriffe Interglazial, Warmzeit und Interstadial nicht genau und verbindlich definiert (Woldstedt \& Duphorn 1974: 13 ff.). Der Begriff Warmzeit für die Bildungsklimate des $F_{4}, F_{3}$ und $F_{2}$ wurde hier aus mehreren Gründen verwendet. Einerseits erfüllt er für ein Interglazial eines der geforderten Hauptmerkmale einer ,intensiven chemischen Verwitterung und Bodenbildung“. Jedoch kann nicht gesagt werden, ob zur Zeit der Bildung des $F_{4}$ bzw. $F_{3}$ bzw. F eine Meerestransgression stattfand, die das Ausmaß der holozänen ganz erreicht hat; vielleicht war dafür die Bildungszeit nicht lang genug. Zwischen den drei Warmzeiten, die von den Böden $\mathrm{F}_{4}-\mathrm{F}_{2}$ repräsentiert werden, gab es sicherlich Vorstöße des nordischen und alpinen Inlandeises, jedoch reichten die Eisvorstöße nach bisheriger Kenntnis nicht bis nach Norddeutschland bzw. in das Alpenvorland - wofür u. a. auch die zeitlich relativ dicht aufeinanderfolgenden drei Warmzeiten mit verantwortlich sein dürften. - Andererseits verbindet man mit dem Begriff Interstadial die Vorstellung von einer kurzfristigen Klimaverbesserung, wie etwa z. Z. des Alleröd-Interstadials. Frühere Auffassungen, daß es in dieser Zeit bereits zur Bildung einer Schwarzerde, Braunerde oder Parabraunerde kam, sind inzwischen widerlegt (vgl. bes. RohDenburg \& MEYer 1968), wobei nochmals betont werden soll (Kap. 3. 1.), daß es wenig nützlich ist, eine geringmächtige Humuszone bzw. Verbraunungszone gleich als Schwarzerde bzw. Braunerde anzusprechen. Da die Tschernoseme bis Tschernosem-Braunerden $\mathrm{F}_{4}$ bis $\mathrm{F}_{2}$ im Karpatenbecken den gleichen (pedochemischen) Verwitterungsgrad aufweisen wie die rezenten Böden gleichen Typs dieses Raumes, kann u. E. für ihre Bildungszeit nicht mehr von einem Interstadial gesprochen werden. 
ren Bereich möglich (Bronger 1973). Dazu muß aber gesagt werden, daß die pedochemische Tonbildungsrate in diesem Bodentyp im trockeneren Bereich (wie heute etwa in der Dobrogea) nach den vorliegenden Daten gering ist (BRONGER 1973). In den hier untersuchten fossilen, primär carbonathaltigen Tschernosemen ist die pedochemische Tonbildung dagegen im allgemeinen mindestens so hoch wie im rezenten Beispiel von Stillfried und nur wenig niedriger als in den degradierten Tschernosemen (Kap. 3.1.). Deshalb darf ihre Bildung in einem klimatischen Bereich angenommen werden, der an den Bildungsbereich des degradierten bis Braunerde-Tschernosems grenzt, zumal er mit diesen Subtypen zusammen in der gleichen stratigraphischen Position wie auch räumlich (vgl. der $\mathrm{F}_{3}$ in Mende, Taf. I) vorkommt. Ein Bildungsklima im kühlen Grenzbereich kommt wegen der beträchtlichen pedochemischen Tonbildungsrate, speziell der hohen Illit- und vor allem Montmorillonitbildung in der Feintonfraktion nicht in Betracht. - Damit soll nicht gesagt sein, daß das Klima z. Z. der Bildung des $F_{3}$ und $\mathrm{F}_{2}$ dem heutigen im inneren Teil des Karpatenbeckens sehr ähnelte. Wahrscheinlich ist, daß das Klima bei etwas geringeren mittleren Jahrestemperaturen, dann aber eher höheren Sommertemperaturen kontinentaler war; der Meeresspiegel hatte - auch verzögert durch die jeweils vorangegangene stärkere Abkühlungsperiode („Lößkaltzeit") - (noch) nicht die Höhe des heutigen erreicht. Darauf deuten auch die im Vergleich zu den holozänen Tschernosemen besonders im Süden wesentlich mächtigeren Tschernoseme in der stratigraphischen Position des $\mathrm{F}_{3}$ und $\mathrm{F}_{2}$ : sowohl in den (sommer)trockenen als in den kalten Zeiten sind die Bodentiere gezwungen, tiefer zu graben. Durch diese Bioturbation („faunal pedoturbation“, JACKSON 1964) entstanden im Laufe der Zeit die mächtigen A-Horizonte. - Schließlich darf auch für die Bildung des $\mathrm{F}_{3}$ und des $\mathrm{F}_{2}$ aus „frischem“, carbonatreichem Löß auf Grund der nicht unbedeutenden pedochemischen Verwitterung und der jeweils großen Mächtigkeit bei vorsichtiger Schätzung einer Dauer von mindestens 5000 Jahren angenommen werden. Dabei seien an die Untersuchungen von ZAKosek (1962), ROHDENBURG \& MEYer (1968) und SMOLíková \& LožEK (1964) erinnert: nach letzteren hat sich in 1500-2000 Jahren zwischen Hallstadt- und Slawen-Zeit unter offener Vegetation ein nur gut $0,5 \mathrm{~m}$ mächtiger Tschernosem gebildet, wobei der Kalkgehalt im A-Horizont nur wenig gegenüber dem CHorizont zurückgegangen ist. - Zur Bildungszeit des $F_{3}$ und des $F_{2}$ dürfte in den Plakorlagen des Karpatenbeckens im allgemeinen eine thermisch noch durchaus anspruchsvolle Waldsteppe mit freilich kontinentalerer Komponente, in den trockenen Teilen eher eine (Löß-Strauch-)Steppe verbreitet gewesen sein.

3. Innerhalb der zwischen den genannten Paläoböden liegenden „Lößkaltzeiten“, in denen das Klima kalt und vor allem trocken gewesen sein dürfte, sind noch einige feuchtere und wärmere Phasen $\mathrm{zu}$ unterscheiden, in denen es an einigen wenigen Stellen ohne nennenswerte Abtragungsphasen zur Bildung von einem noch stärker entwickelten Tschernosęm $\mathrm{F}_{5 \mathrm{a}}$ oder nur $\mathrm{zu}$ einem Initial-Tschernosem $\mathrm{F}_{4 \mathrm{a}}$ im altwürmzeitlichen Löß oder zu ein bis mehreren schwachen, meist synsedimentär entstandenen Syrosemen im jungwürmzeitlichen Löß kam. In den Profilen, in denen letztere deutlicher entwickelt sind (Taf. I), wurden sie als $\mathrm{F}_{1}$ bezeichnet. $\mathrm{Da}$ der Löß zwischen dem $\mathrm{F}_{3}$ und dem $\mathrm{F}_{2}$ maximal bis zu 6-7 m mächtig sein kann und die „Lößkaltzeit“ $\mathrm{z}$ wischen diesen beiden Warmzeiten nach den ${ }^{14} \mathrm{C}$-Daten (Kap. 2.2.) etwa 5000 Jahre dauerte, kann geschlossen werden, daß die Aufwehung von einem Meter Löß, von Extremfällen abgesehen, mindestens 1000 Jahre, im allgemeinen wesentlich länger dauerte.

\subsection{Diskussion der Ergebn is e}

Unsere Ergebnisse und paläoklimatischen Schlußfolgerungen seien zunächst einer jungpleistozänen "Chronologie" vergleichend gegenübergestellt, die aus den ungarischen 
Untersuchungen der paläolithischen Kulturen, der Höhlenablagerungen unter besonderer Berücksichtigung der (Klein)Säugerfauna und zahlreichen ${ }^{14} \mathrm{C}-\mathrm{Daten}$ erstellt wurde (KRETzói \& VÉRtes 1965). Diese Gegenüberstellung sei als erster Versuch betrachtet.

\section{Tabelle 1}

Versuch einer Parallelisierung der jungpleistozänen „Chronologie“ (paläolithische Kulturen, Höhlenablagerungen, (Klein)Säugerfauna und 14C-Daten) von KrEtzó \& VÉRTES (1965) mit den aus lößstratigraphischen und paläopedologischen Untersuchungen gewonnenen Ergebnissen.

S ü t tö - Phase (= „Eem-Interglazial“)

Anwesenheit der (letzten) mediterranen

Arten

Fehlen von arktischen Elementen

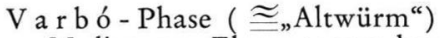

Mediterrane Elemente verschwunden,

Fauna von "gemischtem Waldsteppen-Typ“.

Verbreitet war eine Mousterien-Kultur

(i.w.S.)

$\mathrm{Sub}$ a l y u k - Phase

Rückzug der warmklimatischen Waldarten,

Vorrücken der arktisch-subarktischen Elemente.

Typische Mousterien-Kultur

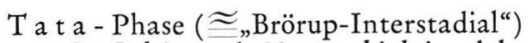
mit Celtis und Mastus bielzi, „d. h. Elemente von interglazialem Charakter".

Nach Mammalia- u. Gastropodenfauna u. Arten des laubabwerfenden Waldes: Julitemperatur von $18-19^{\circ} \mathrm{C}$ (heute $20-21^{\circ} \mathrm{C}$ ); 14C-Alter: $50000 \pm 2500$

S z e le t a - Phase

feuchtes kühles Waldklima im Ungar. Mittelgebirge. ${ }^{14 C}$-Alter $41700 \mathrm{~J}$.

Tok od - Phase „Kältemaximum“ zwischen „Altwürm“ und "Mittelwürm"

I s tá 11 ó sk ö - Phase Nach Fauna und Kultur (Aurignacien II) scharfer Unterschied zur vorangegangenen Phase.

Arktische und definitive Steppenelemente verschwinden, Fauna zeigt "milde Phase von Waldcharakter".

${ }^{14}$ C-Alter $30900 \pm 600$

P i l is zán tó - Phase

Dominanz des Ren ,in einem Mosaik subarktischer Steppe Taiga und Tundra"

A rk a - Phase auch hier unter den Großsäugern das Ren dominant

Palán k - Phase Beginn des Spätglazials
Bildung des $\mathbf{F}_{\mathbf{5}}$ im inneren Karpatenbecken intensiv verwitterte Braunerde, selten ein Braunerde-Lessivé

Bildung des $\mathbf{F}_{5 \mathbf{a}}$ stärker entwickelter Tschernosem

Akkumulation des altwürmzeitl. L ö s s e s $\mathrm{zw}$ ischen $\operatorname{dem} \mathrm{F}_{5}$ and $\operatorname{dem} \mathrm{F}_{4}$

Bildung des $\mathbf{F}_{\mathbf{4}}$

bereits degradierter Tschernosem bis Tschernosem-Braunerde, in Ausnahmen Braunerde; mit gleich hoher pedochemischer Tonbildung wie in heutigen Böden gleichen Typs

Bildung des $\mathbf{F}_{\mathbf{4 a}}$ (?)

schwach entwickelter bzw. Initial-Tschernosem

Akkumulation des $\mathrm{L}$ össes $\mathrm{zw}$ ischen dem $\mathrm{F}_{4}$ und dem $\mathrm{F}_{3}$

Bildung des $\mathbf{F}_{\mathbf{3}}$ und des $\mathbf{F}_{\mathbf{2}}$ meistens noch primär carbonathaltiger Tschernosem, seltener degradierter bis BraunerdeTschernosem mit gleich hoher pedochemischer Tonbildung wie in rezenten Böden gleichen Typs

Akkumulation des jungwürmzeitlichen $\mathrm{L}$ ös s es über $\operatorname{dem} \mathrm{F}_{2}$

die an mehreren Stellen über $10 \mathrm{~m}$ Mächtigkeit erreichte 
Auch manche paläontologische Ergebnisse sprechen eher für das im vorigen Kapitel unter Punkt 2 genannte Ergebnis der Existenz von (mindestens) d r e i a u s g e p r ä g t e n Warmzeiten innerhalb der Würm-Kaltzeit, jedenfalls in SE-Mitteleuropa.

Die bisher fehlende mikromorphologische Untersuchung der basalen Bodenkomplexe „PK III“ und „PK II“ des Profils von Dolní Věstonice (Unter-Wisternitz) führte zur unrichtigen typologischen Ansprache einiger Bodenhorizonte und dadurch zu Fehlinterpretationen auch der malakologischen und damit der paläoklimatischen Bewertung (KLíma et al. 1962). So gehört der blaßbraune Horizont über dem $B_{t}$-Horizont des letztinterglazialen Braunerde-Lessivés nicht als „Eluvialhorizont“ zum liegenden $\mathrm{B}_{\mathrm{t}}$-Horizont, wie auch von anderer Seite verschiedentlich behauptet wurde. Nach dem mikromorphologischen Befund ${ }^{13}$ ) - u. a. regellos verteilte, klastische (primäre) Carbonate, fehlendes Eluvialgefüge - handelt es sich ganz eindeutig um den $\left(\mathrm{A}_{\mathrm{ca}}\right)$-Horizont des hangenden degradierten Tschernosem(restes). Deshalb stammt die Molluskenfauna $\mathrm{nicht}$ aus umgelagerten Resten des letztinterglazialen Bodens, sondern aus dem hangenden degradierten Tschernosem, von hangenden umgelagerten Löß- und Bodensedimenten (Zykl B 1c-f nach KLímA et al. 1962) sowie aus dem ( $\left.\mathrm{A}_{\mathrm{ca}}\right)$-Horizont des darüberliegenden degradierten Tschernosems (Zyklus B 1-g), der aber bereits zum „PK II“ (!) gehört. Die Fauna, die neben Lößarten bzw. Arten, die im Verband der Lößfaunen erscheinen können, auch Waldarten (nach LožEK) enthält, muß aller Wahrscheinlichkeit nach dem Ende der Bildungszeit des noch erhaltenen Restes des degradierten Tschernosems über dem Braunerde-Lessivé zugeordnet werden. Da dieser Boden primär entkalkt ist - mikromorphologisch kenntlich am Fehlen klastischer Carbonate - ist der allergrößte Teil der primären Molluskenfauna aufgelöst, nur der letzte Rest zusammen mit der nachfolgenden kalten Fauna blieb erhalten. Die Molluskenfauna aus den beiden Tschernosemen des „PK II“ (B 1-g und B 2-b-g) enthält nach LožEK neben den wenigen Lößarten (s. o.) in stets sehr geringer Zahl noch Abida frumentum (5 Exemplare allein im oberen Tschernosem), Clausilia pumila, Monachoides incarnata und Euomphalia strigella, jeweils in 1-2 Exemplaren. Auch diese Fauna stellt aller Wahrscheinlichkeit nach nur noch einen Restbestand aus dem Ende der Bildungszeit des oberen bzw. unteren degradierten, d. h. entkalkten Tschernosems zusammen mit der jeweils nachfolgenden kühlen bis kaltzeitlichen Fauna dar. Dennoch weist sie darauf hin, daß zur Bildung der drei degradierten Tschernoseme des „PK III“ und des „PK II“ ein warmes Klima herrschte, was eine Ausbreitung von anspruchsvoller Waldsteppe bzw. Wald ermöglichte.

Diese biostratigraphische und damit paläoklimatische Fehlinterpretation bedingt durch unrichtige paläopedologische Ansprache führte zur z. T. krassen paläoklimatischen Unterbewertung der Tschernoseme. Die Meinung von LožEK (1969: 56), die Schwarzerden repräsentierten Interstadiale, die ,im Vergleich mit den Interglazialen sowie mit der Gegenwart stets noch als kaltzeitlich“ anzusehen seien — „im Rahmen einer Kaltzeit stellen sie jedoch ein günstiges Extrem / die Interstadiale / dar" - erscheint korrekturbedürftig. Auch die Ansicht von Fink (1969), der die Tschernoseme des Stillfrieder Komplexes als interstadiale Böden, „vielleicht besser benannt Oszillationen“ (FINK 1969: 37) ansieht, ist mindestens für den südostmitteleuropäischen Raum kaum haltbar.

Bis vor kurzem wurde wiederholt und mit großem Nachdruck die These vertreten, daß der P a u d o r f e r Boden (loc. typ.), namengebend für das „Paudorfer Interstadial“, die Würmeiszeit in zwei Abschnitte, Früh- und Hochglazial trennt (FINK 1962, 1965b). Der Paudorfer Boden, von dem mehrere ${ }^{14} \mathrm{C}$-Datierungen ein Alter von ca. 30000 Jahren

13) Mikromorphologisch untersucht wurde der basale Teil („PK III + II“) des Profils P4, aus dem auch die Proben für die malakologische Untersuchung von LožEK (In: KLíma et al. 1962) stammen (BRONGER 1973). 
ergaben (FINk 1962, 1965a), wurde mit dem Stillfried-B-Boden (Interstadial) parallelisiert, dessen Alter auf ca. $28000{ }^{14} \mathrm{C}$-Jahre bestimmt worden war (FINK 1962). Beide Paläoböden sind klimatisch als „geringfügige Oszillationen“ interpretiert worden (FINK 1960). - Aus dem C(ea)-Horizont(!) des Paudorfer Bodens entnahm KukLa eine Molluskenfauna, in der LožEK „eine reiche, deutlich interglaziale Gesellschaft mit 24 Arten" bestimmte (Kukla 1969), von denen angeführt werden: Aegopis verticillus, Pagodulina pagodula, Discus perspectivus, Cepaea vindobonensis und Helicodonta obvoluta. Der "Paudorfer Horizont“ soll nach KuKLA (1969) nunmehr „den zusammengeflossenen Boc'enkomplexen PK II + III, wahrscheinlich auch einschließlich PK I" entsprechen. An anderer Stelle (Kukra 1969, Abb. 41 a) wird die o.g. Fauna auch als Banatica-Fauna charakterisiert, obwohl die interglaziale Leitart Helicigona banatica (Rossm.) hier $\mathrm{n} \mathrm{i} \mathrm{ch} \mathrm{t}$ angeführt wird (wie auch nicht in D. Věstonice!). - Die bodenstratigraphische Parallelisierung des noch primär carbonathaltigen Paudorfer Bodens (loc. typ., BRONGER 1973) mit dem basalen, sehr ausgeprägten Braunerde-Lessivé von Dolní Věstonice ist aus bodengeographischen Gründen denkbar unwahrscheinlich, zumal das Paudorfer Profil im feuchteren sog. „Übergangsgebiet“, der Aufschluß von Dolní Věstonice dagegen in der sog. „trockenen Lößlandschaft“ liegt (FINK 1956, 1960, 1962, 1965, 1969). Durchaus möglich ist dagegen, daß der Paudorfer Boden einem der Böden des „PK II“ entspricht, was auch schon früher vermutet wurde (RohDenburg \& MEYer 1966, Bronger 1970), dem dann vielleicht die o. g. warmzeitliche Fauna zuzuordnen ist.

Aus dem Lößprofil von Bötzingen/Kaiserstuhl beschrieb KHODARY-EissA (1968) über dem jüngsten fossilen Braunerde-Lessivé eine Verbraunungszone“ mit bis $\mathrm{zu} \mathrm{1,6 \%} \mathrm{Hu}$ musgehalt, die zwar einen $\mathrm{Ca}-H o r i z o n t$ aufweist, wahrscheinlich aber noch primär carbonathaltig ist (KHODARY-EIssa 1968: $123 \mathrm{ff}$.). Aus diesem Boden bestimmte Münzing (1969) eine warmzeitliche Fauna, die insbesondere Aegopinella ressmanni, Aegopis spez., Discus perspectivus, Drepanostoma nautiliformae, Pagodulina sparsa und Clausilia pumila enthält. Deshalb stuft MünzING diese Verbraunungszone in das Riß/Würm-Interglazial ein. Das ist - ähnlich wie beim Paudorfer Boden - aus paläopedologischen und bodengeographischen Gründen recht unwahrscheinlich; die Bötzinger Verbraunungszone ist am ehesten - wie das auch KHODARY-Eissa tut - mit der würmzeitlichen „Unteren Verbraunungszone" im nahe gelegenen Heitersheimer Profil (BRONGER 1966) chronostratigraphisch zu parallelisieren. Das Riß/Würm-Interglazial wird in mehreren großen Lößprofilen dieses Raumes (Bötzingen, Riegel, Heitersheim, Buggingen, vgl. Bronger 1966, 1969, 1969/70; KHODARY-EIssA 1968) durch einen sehr mächtigen, ausgeprägten BraunerdeLessivé repräsentiert.

Wie einleitend gesagt, war es weniger das Ziel dieser Arbeit, zu bestehenden Hypothesen neue hinzuzufügen, sondern die hier erhaltenen Ergebnisse durch aussagekräftige qualitative und quantitative Untersuchungsmethoden zu belegen, die weit über den Geländebefund hinausgehen. Die daraus sich ergebenden Schlußfolgerungen mögen Anregungen zu weiteren Diskussionen über den Klimaablauf vor allem des Jungpleistozäns geben, die bei weitem noch nicht als abgeschlossen betrachtet werden können.

\section{Danks a gung}

Die Geländeruntersuchungen wurden durch Reisebeihilfen der DFG unterstützt. Ein großer Teil der Laborarbeiten konnte im Rahmen des DFG-Schwerpunktprogramms "Tonmineralogie“ durchgeführt werden, an dem neben dem Verfasser Prof. Schroeder und Dr. KalK vom Bodenkundlichen Institut der Universität Kiel beteiligt sind; die gemeinsamen, detaillierten Untersuchungsergebnisse sind in GEODERMA im Druck. Für die vielfältige Unterstützung bin ich der DFG sehr dankbar. 


\section{Schriftenverzeichnis}

André́nszKy, G. \& S. Kovícs, E. (Hrsg.): Gliederung und Ớkologie der jüngeren Tertiärfloren Ungarns. - A Magyar Állami Földtani Intézet Evkönyve XLIV 1, 1-326, Budapest 1955.

Arnaud, R. J. St. and Whiteside, E. P.: Physical breakdown in relation to soil development. J. Soil Science 14, 267-281, 1963.

Bronger, A.: Lösse, ihre Verbraunungszonen und fossilen Böden. Ein Beitrag zur Stratigraphie des oberen Pleistozäns in Südbaden. - Schr. Geogr. Inst. Universität Kiel XXIV H. 2, 104 S., Kiel 1966.

- : Zur Klimageschichte des Quartärs von Südbaden auf bodengeographischer Grundlage. Peterm. Geogr. Mitt. 113, 112-124, Gotha 1969.

- : Zur Mikromorphogenese und zum Tonmineralbestand quartärer Lößböden in Südbaden. Geoderma 3, 281-320, Amsterdam 1969/70.

- : Zur Mikromorphologie und zum Tonmineralbestand von Böden ungarischer Lößprofile. - Eiszeitalter u. Gegenwart 21, 122-144, O'hringen 1970.

- : Zur Genese und Verwitterungsintensität fossiler Lößböden in Jugoslawien. — Paleopedology, Origin. Nature and Dating of Paleosols, Symposium Amsterdam 1970 (ed. by D. H. YAALON), 271-281, Jerusalem 1971.

- : Zur quartären Klima- und Landschaftsentwicklung des Karpatenbeckens auf (paläo)pedologischer und bodengeographischer Grundlage. - Habilitationsschrift, 269 S., Kiel 1973 (erscheint in: Kieler Geographische Schriften 45 (im Druck).

- : Zur postpedogenen Veränderung bodenchemischer Kenndaten insbesondere von pedogenen Eisenoxiden in fossilen Lößböden. - Transact. X. Internat. Congress of Soil Science VI(II), 429-441, Moskau 1974.

Bronger, A., Graf v. Reichenbach, H. \& Schroeder, D.: Uber den Tonmineralbestand des Lößprofils von Heitersheim, Südbaden. - Z. Pflanzenernähr., Düng., Bodenkde. 113, 193-203, Weinheim 1966.

BrunNaCker, K.: Kriterien zur relativen Datierung quartärer Paläoböden? - Bemerkungen auf Grund einer Arbeit von K. Metzger. - Z. Geomorph. NF 14, 354-360, Berlin u. Stuttgart 1970 .

Cones, A.: Formatiuni cuaternare in Dobrogea. (Loessuri si paleosoluri). - Editura Academiei Republicii Socialiste Romania, 234 S., Bucuresti 1970.

FINK, J.: Zur Korrelation der Terrassen und Lösse in Österreich. - Eiszeitalter u. Gegenwart 7, 49-77, Öhringen 1956.

— : Leitlinien einer österreichischen Quartärstratigraphie. - Mitt. Geol. Ges. Wien 53, 249-266, Wien 1960.

— : Die Gliederung des Jungpleistozäns in Österreich. — Mitt. Geol. Ges. Wien 54 1-25, Wien 1962.

— : Die Subkommission für Lößstratigraphie der Internationalen Quartärvereinigung. — Eiszeitalter u. Gegenwart 16, 264-275, OOhringen 1965 (1965a).

- : The Pleistocene in Eastern Austria. - Internat. Studies on the Quaternary, ed. by H. E. Wright and D. G. Frye, 197-199, Boulder, Colorado 1965 (1965b).

- : Bemerkungen zu den Exkursionen über das Problem „Löß-Periglazial-Paläolithikum“. - In: Loess-Periglaciaire-Paleolithique sur le territoire de l'Europe Moyenne et Orientale, 33-54, Moskau 1969.

Fotakiewa, E.: Die Fossilböden im Löß von Bulgarien. - Arbeitstagung der INQUA-Lößkommission 1. Teil, 53-79, Sofia 1970 (1970a).

- : Die Lößprofile von Zlatija, Metschka, Zarevetz, Slomer, Paskalevetz, Tutrakan I und II in Nordbulgarien. - Arbeitstagung der INQUA-Lößkommission 2. Teil, 3-125, zahlr. Abb., Sofia 1970 (1970b).

Franke, H. W. \& GeYh, M. A.: Zur 14C-Datierung des Würm II/III-Interstadials mit Hilfe von Radiokohlenstoffmessungen an Höhlensinter und Schlußfolgerungen für die Wasseraltersbestimmung. - Eiszeitalter u. Gegenwart 20, 72-75, Öhringen 1969.

GeYh, M. A., Schweitzer, F., Vértes, L. \& Vogel, J. G.: A magyarórszagi würmi eljegesedés úy kronológiai adatai (Neue chronologische Angaben zur Würm-Vereisung in Ungarn). - Földr. Ért. XVIII, 5-18, Budapest 1969.

HaAse, G., Lieberoth, J., Ruske, R. et al.: Sedimente und Paläoböden im Lößgebiet. - Peterm. Geogr. Mitt., Ergh. Nr. 274, 99-212, Gotha 1970. 
HÄDRICH, F.: Zur Anwendbarkeit einiger bodenkundlicher Untersuchungsmethoden in der paläopedologischen und quartärgeologischen Forschung unter besonderer Berücksichtigung der Untersuchung von Proben aus Lößaufschlüssen. - Ber. Naturf. Ges. Freiburg i. Br. 60, 103-137, Freiburg 1970/71.

JaCkson, M. L.: Chemical Composition of Soils. - In: Chemistry of the Soil (ed. by F. E. BeAr), 71-141, New York 1964 (19673).

Khodary-EIssa, O.: Feinstratigraphische und pedologische Untersuchungen an Lößaufschlüssen im Kaiserstuhl (Südbaden). - Freiburger Bodenkdl. Abh. 2, 149 S. mit Anhang (Tabellen u. Abb.), Freiburg i. Br. 1968.

KLíma, B., Kukla, J., LožeK, V. \& DE Vries, H.: Stratigraphie des Pleistozäns und Alter des paläolithischen Rastplatzes in der Ziegelen von Dolní Věstonice (Unter-Wisternitz). - Anthropozoikum XI, 93-145, Prag 1962.

Kretzói, M.: Quaternary Geology and the Vertebrate Fauna. - Acta Geol. Hung. II, 67-79, Budapest 1953.

- : Die altpleistozänen Wirbeltierfaunen des Villanyer Gebirges. - Geologica Hungarica 27, 264 S., Budapest 1956.

Kretzói, M. \& Vértes, L.: The Role of Vertebrate Faunae and Palaelithic Industries of Hungary in Quaternary Stratigraphy and Chronology. - Acta Geol. IX, 125-143, Budapest 1965.

Kretzói, M. \& Krolopp, E.: Az Alföld harmadkor végi és negyedkori rétegtana az öslénytani adatok alapján (Oberpliozäne und quartäre Stratigraphie des Alföld [Große Ungarische Tiefebene]) aufgrund paläontologischer Angaben. - Földr. Ért. XXI, 133-158, Budapest 1972.

Kubiena, W. L.: Zur Mikromorphologie, Systematik und Entwicklung der rezenten und fossilen Lößböden. - Eiszeitalter u. Gegenwart 7, 102-112, Öhringen 1956.

- : Zur Mikromorphologie und Mikromorphogenese der Lößböden Neuseelands. - Soil Micromorphology (ed A. Jongerius), 219-235, Amsterdam 1964.

KukLA, J.: Survey of Czechoslowak Quaternary Sedimentation Cycle. - Inst. Geol., Prace XXXIV, Czwartorzed Europy Srodkowey i Wschodniej, Cześj I, 145-154, Warszawa 1961.

- : Die zyklische Entwicklung und die absolute Datierung der Löß-Serien. - Periglazialzone, Löß und Paläolithikum der Tschechoslowakei (Hrsg. J. Demek u. J. KukLA), 75-95, Brno 1969.

LASKarev, V.: O. stratigrafiji knartarnih naslaga Vojvodine. - (Sur la stratigraphie des déposits quaternaires de la Vojvodina [Yougoslavie]). - Anales Géol. de la Péninsule Balkanique XIX, 1-18, Beograd 1951.

LožEK, V.: Paläontologische Charakteristik der Löß-Serien. - Periglazialzone, Löß und Paläolithikum der Tschechoslowakei (Hrsg. J. Demek u. J. Kunta), 43-59, Brno.

Marković-Marjanović, J.: Profils de loess sur la rive droite du Danube près du village Neštin (Bassin Pannonien). - Zbornik Matice srpske 7, 5-20, Novi Sad 1954.

- : Le Loess en Yougoslavie. - Report of the Int. Congr. on Quaternary, Warsaw 1961, Vol. IV, Symposium on Loess, 551-570, Łódź 1964.

- : Les Profils de loess du bassin pannonique, région classique du loess de Yougoslavie. - Bull. de l'Association française pour l'étude du Quaternaire, 165-170, Paris 1969.

MüNZING, K.: Quartäre Molluskenfaunen aus dem Kaiserstuhl. - Jh. geol. L.Amt Baden-Württemberg 11, 87-115, Freiburg i. Br. 1969.

PÉCSI, M.: Ten years of physico-geographic research in Hungary. - Studies in Geography 1, 132 S., Budapest 1964.

— : Der Lößaufschluß von Mende. - Földr. Közlem. 89, 332-338, Budapest 1965.

- : Lösse und lößartige Sedimente im Karpatenbecken und ihre lithostratigraphische Gliederung. — Peterm. Geogr. Mitt. 110, 176-189, 241-252, Gotha 1966.

PÉCSI, M. \& SzEBÉnYI, E.: Guide-Book für Loess-Symposium in Hungary. - IGU, European Regional Conference and INQUA-Commission on Loess, Budapest 1971.

PÉCsi, M. \& Pevzner, M. A.: Paleomagnetic measurements in the loess-sequences at Paks and Dunaföldvár, Hungary. - Földr. Közlem., 215-219, Budapest 1974.

Rohdenburg, H. \& MeYer, B.: Zur Feinstratigraphie und Paläopedologie des Jungpleistozäns nach Untersuchungen an südniedersächsischen und nordhessischen Lößprofilen. - Mitt. Dtsch. Bodenkdl. Ges. 5, 1-137, Göttingen 1966.

— : Zur Datierung und Bodengeschichte mitteleuropischer Oberflächenböden (Schwarzerde, Parabraunerde, Kalksteinbraunlehm): Spätglazial oder Holozän? — Göttinger Bodenkdl. Ber. 6, 127-212, Göttingen 1968. 
Scheffer, F., Meyer, B. \& Gebhardt, H.: Pedochemische und kryoklastische Verlehmung (Tonbildung) in Böden aus kalkreichen Lockersedimenten (Beispiel Löß). - Z. Pflanzenernähr., Düng., Bodenkde. 114, 77-89, Weinheim 1966.

Semmel, A.: Uber Prä-Würm-Lösse in Hessen. - Notizbl. hess. L.-Amt Bodenforsch. 95, 239241, Wiesbaden 1967.

- : Der Stand der Eiszeitforschung im Rhein-Main-Gebiet. — Rhein-Mainische Forsch. 78, 9-56, Frankfurt 1974.

SEPpÄLÄ, M. : Stratigraphy and material of the loess layers at Mende, Hungary. - Bull. Geol. Soc. Finland 43, 109-123, 1971.

SмоцíкоvÁ, L.: Gesetzmäßigkeiten der Bodenentwicklung im Quartär. - Eiszeitalter u. Gegenwart 22, 156-177, Ohringen 1971.

Smolíkoví, L. \& LožEk, V.: The Holocene Soil Complex of Litomerice. - Antropozoikum, rada A, sv. 2, 41-56, Prag 1964.

SüMEghy, J.: Zusammenfassende Beschreibung des Pleistozäns von Ungarn. - Antropozoikum V, 455-461, Prag 1956.

Woldstedt, P. \& Duphorn, K.: Norddeutschland und angerenzende Gebiete im Eiszeitalter, 500 S,. Stuttgart 1974.

Zakosek, H.: Zur Genese und Gliederung der Steppenböden im nördlichen Oberrheintal. - Abh. hess. L.-Amt Bodenforsch. 37, 1-46, Wiesbaden 1962.

Zólyomi, B.: Map of natural vegetation reconstructed, 1:1,5 Mill. - In: National Atlas of Hungary, 31, Budapest 1967.

- : Budapest és környékének termeszetes novénytakarója (Natürliche Pflanzendecke von Budapest und seiner Umgebung). - Budapest természeti kepe, 511-642, Budapest 1958.

Manuskript eingeg. 25. 8. 1975.

Anschrift des Verf.: Dr. habil. A. Bronger, Geograph. Institut der Universität Kiel, 23 Kiel, Olshausenstraße 40-60. 